orn

OAK RIDGE

NATIONAL

LABORATORY

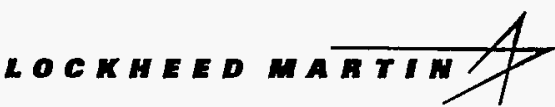

MANAGED BY

LOCKHEED MARTIN ENERGY SYSTEMS, INC. FOR THE UNITED STATES

DEPARTMENT OF ENERGY

\section{RECEIVED \\ NOV 211995 \\ OSTI \\ Energy Conservation \\ Opportunities in Small \\ Commercial Buildings}

M. M. Abraham

J. M. MacDonald

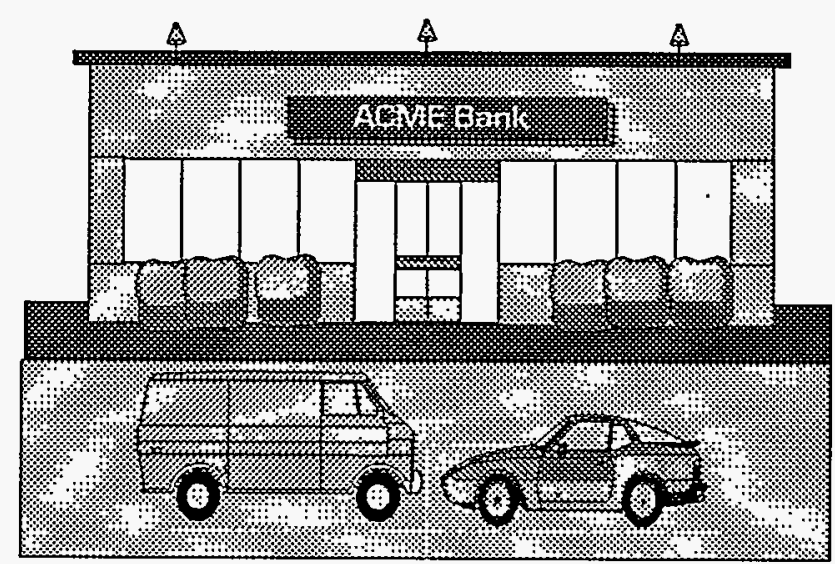

Prepared for the

Office of Buildings Technology

Existing Buildings Efficiency Research Program

U.S. Department of Energy

under

contract No. DE-AC05-84OR21400 
This report has been reproduced directly from the best available copy.

Available to DOE and DOE contractors from the Office of Scientific and Technical Information, P.O. Box 62, Oak Ridge, TN 37831; prices available from (615) 576-8401, FTS 626-8401.

Available to the public from the National Technical Information Service, U.S. Department of Commerce, 5285 Port Royal Rd., Springfield, VA 22161.

This report was prepared as an account of work sponsored by an agency of the United States Government. Neither the United States Government nor any agency thereof, nor any of their employees, makes any warranty, express or implied, or assumes any legal liability or responsibility for the accuracy, completeness, or usefulness of any information, apparatus, product, or process disclosed, or represents that its use would not infringe privately owned rights. Reference herein to any specific commercial product, process, or service by trade name, trademark, manufacturer, or otherwise, does not necessarily constitute or imply its endorsement, recommendation, or favoring by the United States Government or any agency thereof. The views and opinions of authors expressed herein do not necessarily state or reflect those of the United States Government or any agency thereof. 


\title{
Energy Conservation Opportunities in Small Commercial Buildings
}

\author{
M. M. Abraham \\ J. M. MacDonald
}

August 1995

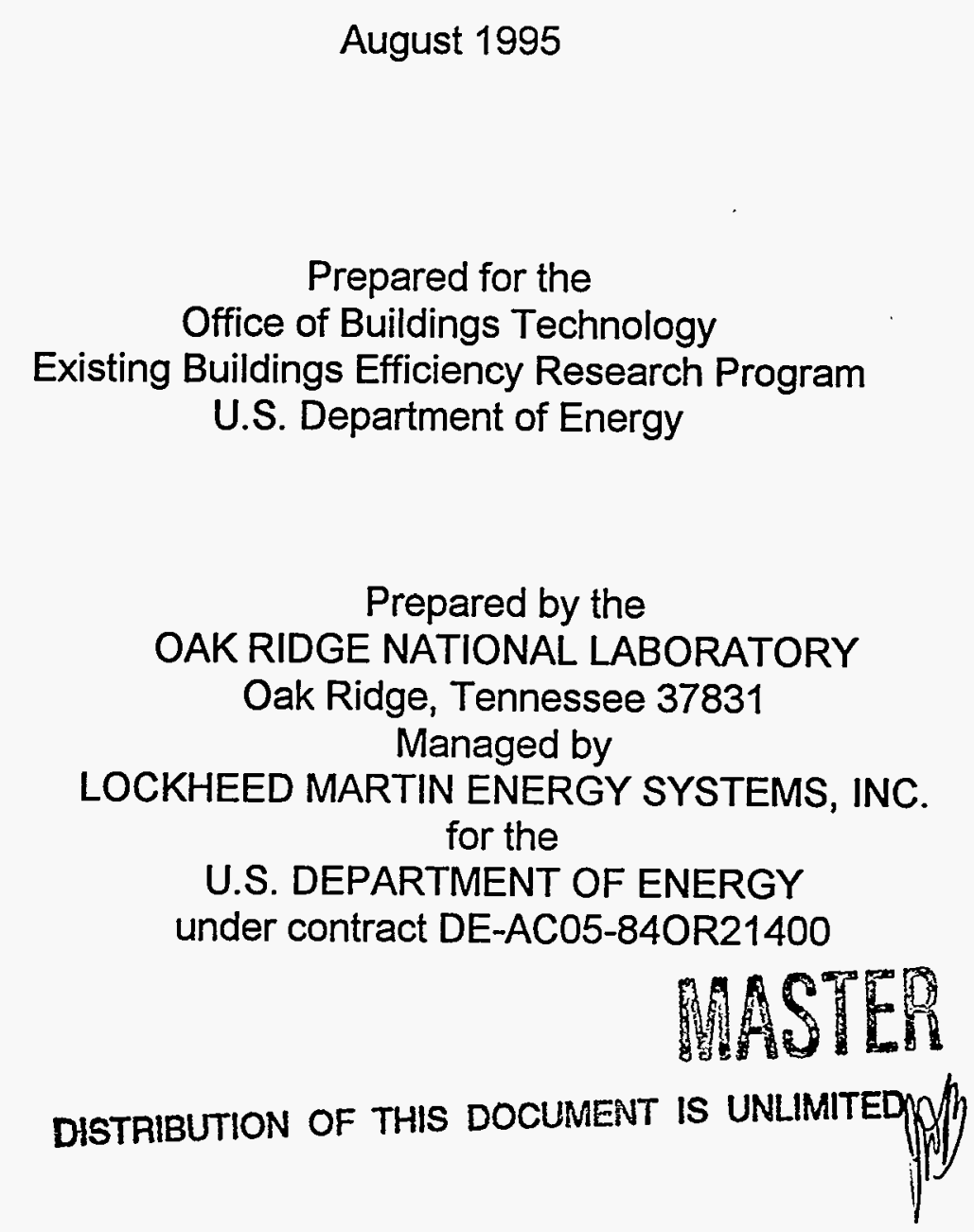




\section{CONTENTS}

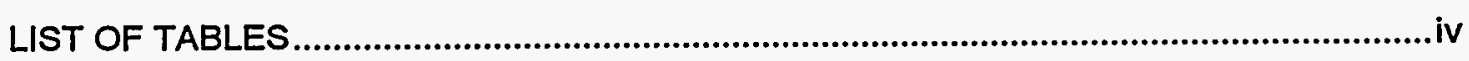

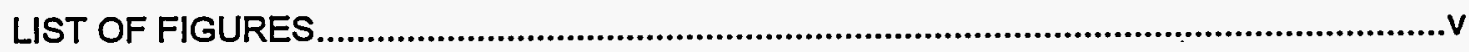

EXECUTIVE SUMMARY ................................................................................................

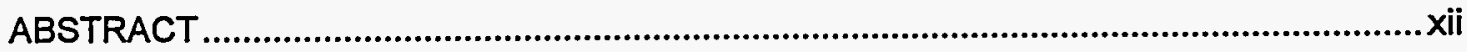

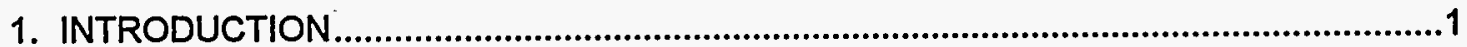

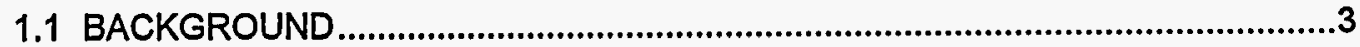

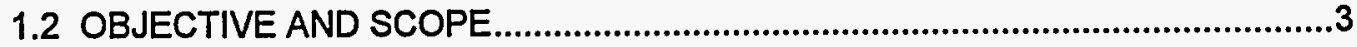

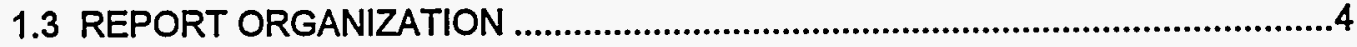

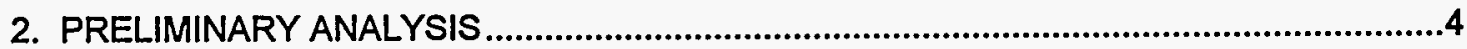

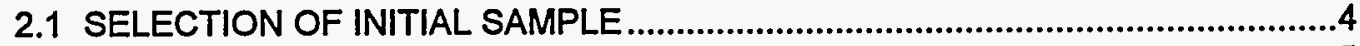

2.2 ENERGY CONSUMPTION, DEMAND, AND LOAD INDICES ...............................5

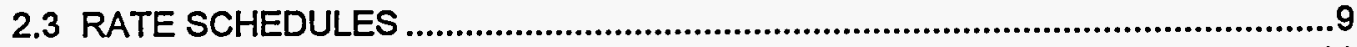

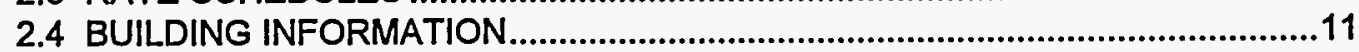

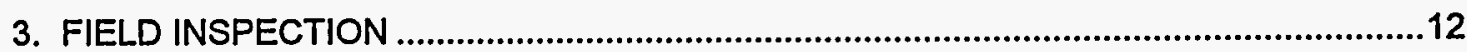

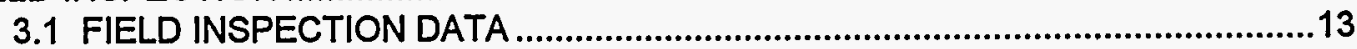

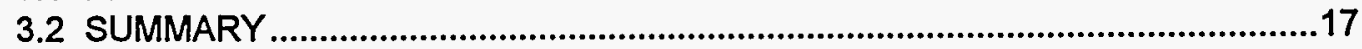

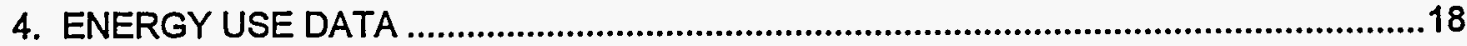

4.1 ENERGY USE DATA ANALYSIS FOR RESTAURANT \#1 ...............................18

4.1.1 Monthly Data .......................................................................................... 18

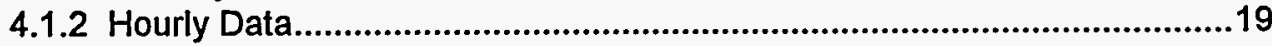

4.2 ENERGY USE DATA ANALYSIS FOR CLOTHING STORE ..........................20

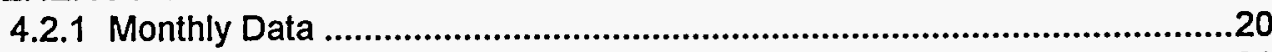

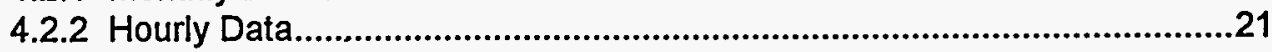

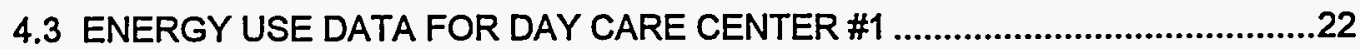

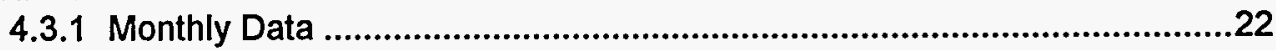

4.3.2 Hourly Data.........................................................................................23

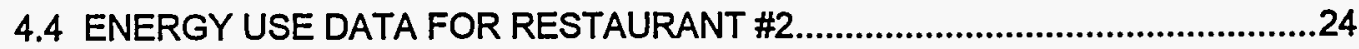

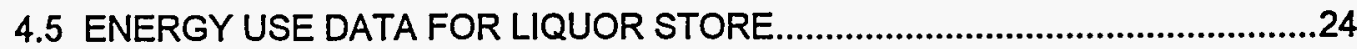

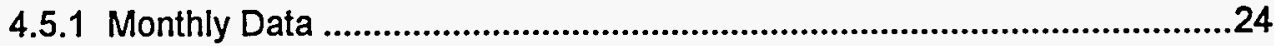

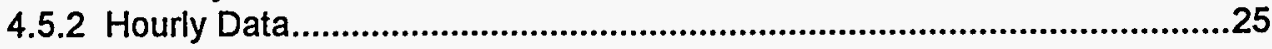

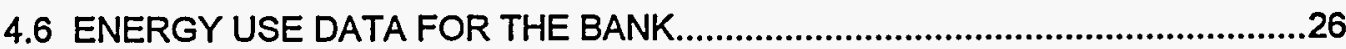

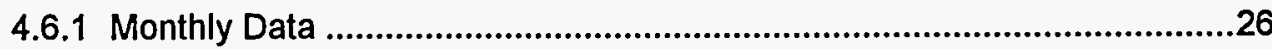

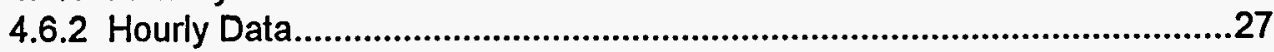

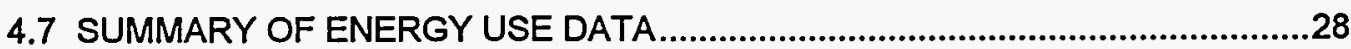

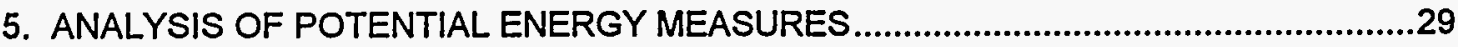

5.1 POTENTIAL ENERGY MEASURES FOR RESTAURANT \#1 ...........................29

5.2 POTENTIAL ENERGY MEASURES FOR CLOTHING STORE .........................31

5.3 POTENTIAL ENERGY MEASURES FOR DAY CARE CENTER \#1......................33

5.4 POTENTIAL ENERGY MEASURES FOR LIQUOR STORE ................................35

5.5 POTENTIAL ENERGY MEASURES FOR BANK ...............................................36

5.6 SUMMARY OF POTENTIAL MEASURES .........................................................38

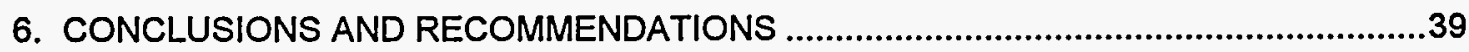

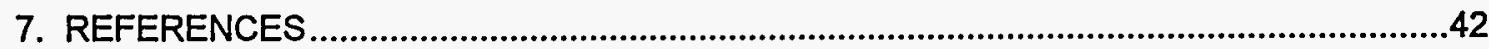




\section{LIST OF TABLES}

Table S.1 Buildings selected for ORNL/Duke Power small commercial demonstration ....... viii

Table S.2 Summary of potential energy, demand and cost savings, per scenario ................. ix

Table 2.1 Monthly energy use indices used to target demonstration buildings.......................5

Table 2.2 Buildings selected for ORNL/Duke Power small commercial demonstration......... 12

Table 3.1 Site audit information for Restaurant \#1 ....................................................... 13

Table 3.2 Site audit information for Clothing Store ........................................................ 14

Table 3.3 Site audit information for Day Care Center \#1 ................................................ 15

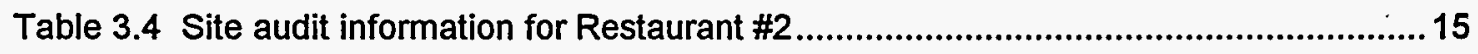

Table 3.5 Site audit information for Liquor Store............................................................. 16

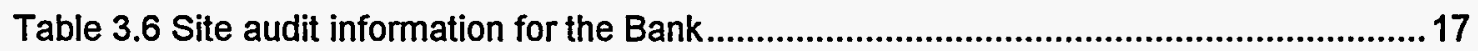

Table 5.1 Summary of potential energy, demand and cost savings, per scenario ................39 


\section{LIST OF FIGURES}

Figure 1.1 Percent of buildings with efficiency features, by floor area ................................ 1

Figure 2.1 Distribution of Monthly Consumption, in $\mathrm{W} / \mathrm{ft}^{2}$, for candidate buildings................6

Figure 2.2 Distribution of Monthly Demand, in $\mathrm{W} / \mathrm{ft}^{2}$, for candidate buildings ......................6

Figure 2.3 Distribution of Monthly ELF's for candidate buildings ...................................

Figure 2.4 Distribution of Monthly OLF's, for candidate buildings.......................................

Figure 2.5 Duke Power schedules GA and G, effective July 1, 1993.............................. 10

Figure 2.6 Duke Power schedule OPT, effective July 1, 1993....................................11

Figure 4.1 Monthly On-Peak Consumption and Demand for Restaurant \#1 ........................ 18

Figure 4.2 Monthly Off-Peak Consumption and Demand for Restaurant \#1 .......................19

Figure 4.3 Monthly energy-use indices for Restaurant \#1 ...........................................19

Figure 4.4 (a) Hourly end-use consumption, January 1 - 7, 1993, Restaurant \#1..................20

Figure 4.4 (b) Hourly end-use consumption, July 8 - 14, 1993, Restaurant \#1 ....................20

Figure 4.5 Monthly consumption and demand for Clothing Store ....................................20

Figure 4.6 Monthly energy indices for Clothing Store ..................................................21

Figure 4.7 (a) Hourly end-use consumption, January 22 - 31, 1993, Clothing Store ..............22

Figure 4.7 (b) Hourly end-use consumption, July $1-7,1993$, Clothing Store ....................22

Figure 4.8 Monthly consumption and demand for Day Care Center \#1 ..............................22

Figure 4.9 Monthly energy indices for Day Care Center \#1 .............................................23

Figure 4.10 (a) Hourly end-use consumption, January 22 - 31, 1993, Day Care Center \#1....24

Figure 4.10 (b) Hourly end-use consumption, July 8 - 14, 1993, Day Care Center \#1...........24

Figure 4.11 Monthly consumption and demand for Liquor Store ......................................24

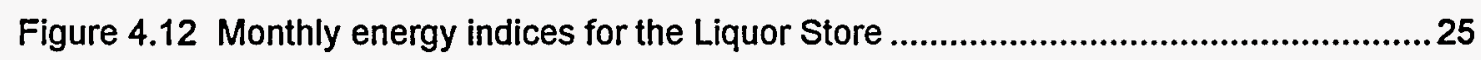

Figure 4.13 (a) Hourly end-use consumption, January 15 - 21, 1993, Liquor Store..............26

Figure 4.13 (b) Hourly end-use consumption, July 1 - 7, 1993, Liquor Store .......................26

Figure 4.14 Monthly consumption and demand for Bank ...........................................26

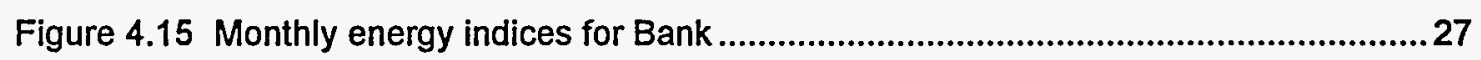


Figure 4.16 (a) Hourly end-use consumption, January 8 - 14, 1993, Bank..........................28

Figure 4.16 (b) Hourly end-use consumption, July 8 - 14, 1993, Bank................................28

Figure 5.1 Monthly energy consumption comparison of actual and simulated models,

Restaurant \#1

Figure 5.2 Monthly demand comparison of actual and simulated models,

Restaurant \#1 30

Figure 5.3 Monthly energy consumption comparison of actual and simulated models, Clothing Store

Figure 5.4 Monthly demand comparison of actual and simulated models, Clothing Store .... 32

Figure 5.5 Monthly utility cost comparisons of base and simulated models, Clothing Store.. 33

Figure 5.6 Monthly energy consumption comparison of actual and simulated models, Day Care Center \#1

Figure 5.7 Monthly demand comparison of actual and simulated models, Day Care Center \#1 34

Figure 5.8 Monthly utility cost comparisons of actual and simulated models, Day Care Center \#1

Figure 5.9 Monthly energy consumption comparison of áctual and simulated models, Liquor Store .35

Figure 5.10 Monthly demand comparison of actual and simulated models, Liquor Store.

Figure 5.11 Monthly utility cost comparison of actual and simulated models, Liquor Store

Figure 5.12 Monthly energy consumption comparison of actual and simulated models, Bank.

Figure 5.13 Monthly demand comparison of actual and simulated models, Bank. .37

Figure 5.14 Monthly utility cost comparison of actual and simulated models, Bank 


\section{EXECUTIVE SUMMARY}

\section{S.1 OBJECTIVE AND SCOPE}

Nearly three-fourths of the commercial buildings in the United States have floor areas of less than 10,000 square feet (EIA 1994). These smaller buildings are responsible for approximately $30 \%$ of the energy expenditures of the whole commercial sector, (about 2.6 quads of primary energy). While considerable potential for energy conservation exists in smaller commercial buildings, several obstacles have prevented conservation programs from being implemented. Duke Power Company has expressed an interest in expanding their demand side management program into the small commercial area. The U.S. Department of Energy, through Oak Ridge National Laboratory (ORNL), is also interested in determining the highest level of savings that can be obtained at a reasonable cost. In a joint effort by Duke Power and ORNL, a sample of small commercial buildings in the Duke Power North Carolina service territory were studied to determine significant conservation opportunities.

\section{S.2 DEMONSTRATION SITES}

The original list supplied by Duke Power contained over 60 small commercial buildings. Targeting methods, including energy consumption, demand, and load factor indices, were used to reduce this list down to six sample buildings. The buildings selected were all under 7,000 square feet and included a clothing store, a liquor store, two restaurants, a day-care center, and a small bank. Two of the buildings, the bank and the clothing store, were actually leased spaces in strip-malls, while the other four were freestanding. Some of the buildings had commercial contracts for maintenance work, however none of the representatives interviewed seemed very energy-conscious about their own building. 


\section{S.3 ANALYSIS APPROACH}

Duke Power supplied ORNL with hourly end-use data and monthly utility bills spanning from July 1992 through August 1994. Customer surveys were also provided which included information on floor area, operating hours, occupancy, and major equipment. The monthly billing data were used to select six demonstration sites from the list of over 60 candidates. This was done using box-plot distributions of annual energy use indices for each building. These energy use indices included energy and demand densities, in $\mathrm{W} / \mathrm{ft}^{2}$, and electrical and occupancy load factors. Hourly data were then used to verify the targeting process developed with the monthly data. Table S.1 presents the buildings selected along with information on floor area, annual peak demand, consumption, and utility costs.

\begin{tabular}{||c|c|c|c|c|c||}
\hline Identifier & Function & $\begin{array}{c}\text { Floor } \\
\text { Area }\end{array}$ & $\begin{array}{c}\text { Annual } \\
\text { Peak kW }\end{array}$ & $\begin{array}{c}\text { Annual } \\
\mathbf{k W h}\end{array}$ & $\begin{array}{c}\text { Annual } \\
\text { Utility Cost }\end{array}$ \\
\hline Restaurant \#1 & Restaurant & $6,370 \mathrm{ft}^{2}$ & 78 & 303,400 & $\$ 16,075$ \\
\hline Clothing Store & Retail & $3,150 \mathrm{ft}^{2}$ & 45 & 129,171 & $\$ 8,100$ \\
\hline Day Care Center \#1 & Day-Care & $4,000 \mathrm{ft}^{2}$ & 33 & 96,320 & $\$ 6,330$ \\
\hline Restaurant \#2 & Restaurant & $4,420 \mathrm{ft}^{2}$ & 65 & 227,900 & $\$ 12,200$ \\
\hline Liquor Store & Retail & $2,800 \mathrm{ft}^{2}$ & 21. & 73,861 & $\$ 5,704$ \\
\hline Bank & Bank Branch Office & $3,700 \mathrm{ft}^{2}$ & 35 & 79,680 & $\$ 5,396$ \\
\hline
\end{tabular}

Table S.1 Buildings selected for ORNL/Duke Power small commercial demonstration

The hourly end-use data were also used in preparation for site visits to aid audit team members in identifying and locating significant building loads. Approximately two hours were spent on each visit by a team consisting of one Duke Power and two ORNL personnel. Following an established audit protocol, (MacDonald 1989), audit members recorded site information including thermostat set points, lighting type, capacity, and level, and HVAC 
equipment data. Interviews with building representatives, usually day-managers, provided information on operating hours and building operation, while informing them of conservation opportunities for their building.

With hourly, monthly, and audit data on-hand, the ORNL team analyzed each of the six buildings for energy conservation opportunities. First-order energy simulation models were developed for each building using the DOE-2.1D simulation software. These models used Typical Meteorological Year (TMY) weather data and were compared to actual building billing data from July 1993 through June 1994. Conservation retrofit measures included: HVAC control, HVAC equipment replacement, and lighting system upgrade. Energy simulation results provided quantitative information on the effects of the different retrofits on demand and consumption. Using the results from the simulation, utility cost savings were estimated for each building based on their respective rate structures.

\section{S.4 RETROFIT MEASURES}

Table S.2 lists the energy, demand and cost savings, for each building, pertaining to individual retrofit scenarios."

\begin{tabular}{|c|c|c|c|c||}
\hline Name & Lighting & Controls & HVAC & Total \\
\hline Restaurant \#1 & $15,300 \mathrm{kWh}$, & $37,000 \mathrm{kWh}$, & & $52,000 \mathrm{kWh}, 3 \mathrm{~kW}$ \\
& $3 \mathrm{~kW}$ & $-1.2 \mathrm{~kW}$ & & \\
\hline Clothing Store & $18,000 \mathrm{kWh}$, & $22,000 \mathrm{kWh}$, & $17,000 \mathrm{kWh}$, & $70,600 \mathrm{kWh}$, \\
& $3.8 \mathrm{~kW}, \$ 900$ & $-2.7 \mathrm{~kW}, \$ 1,070$ & $10 \mathrm{~kW}, \$ 900$ & $30 \mathrm{~kW}, \$ 3,600$ \\
\hline Day Care Center \#1 & & $26,500 \mathrm{kWh}$, & $17,000 \mathrm{kWh}$, & $38,000 \mathrm{kWh}$, \\
& & $-8 \mathrm{~kW}, \$ 1,200$ & $9 \mathrm{~kW}, \$ 850$ & $3.4 \mathrm{~kW}, \$ 1,850$ \\
\hline Liquor Store & $26,600 \mathrm{kWh}$, & $6,500 \mathrm{kWh}$, & & $34,700 \mathrm{kWh}$, \\
& $6 \mathrm{~kW} \$ 1,500$ & $-2 \mathrm{~kW}, \$ 290$ & & $6.6 \mathrm{~kW}, \$ 1,950$ \\
\hline Bank & $12,000 \mathrm{kWh}$, & $8,200 \mathrm{kWh}$, & & $21,800 \mathrm{kWh}$, \\
& $4,8 \mathrm{~kW}, \$ 740$ & $-12 \mathrm{~kW}, \$ 210$ & & $2.8 \mathrm{~kW}, \$ 950$ \\
\hline
\end{tabular}

Table S.2 Summary of potential energy, demand and cost savings, per scenario

\footnotetext{
* One of the restaurants selected withdrew from the program and was not included in the retrofit analysis.

** Rate structure not available for study
} 
Lighting retrofits consisted of updating older systems, with new, more-efficient equipment. Suggestions were made to replace all $T-12$ fluorescent, magnetic ballast fixtures with low-wattage T-8 lamps and 4-lamp electronic ballasts. Several buildings used incandescent spotlighting, and in areas where these fixtures could not be replaced with fluorescents, lower wattage spotlights were recommended. For the five buildings studied, four were recommended for lighting retrofits. The combined savings from lighting retrofits is estimated to be $72,000 \mathrm{kWh}$ and $17.6 \mathrm{~kW}$. This represents a reduction in consumption of $11 \%$, and in demand of $8 \%$.

While several of the building managers claimed to manually regulate their HVAC systems, a great deal of after-hour consumption still occurs in the buildings examined. The control retrofits suggested for each building employ cooling and heating setbacks, typically to $80^{\circ} \mathrm{F}$ and $60^{\circ} \mathrm{F}$, respectively. Controls were recommended for every site visited. The total estimated consumption savings associated with control installations were $100,200 \mathrm{kWh}$, or $23 \%$ of the initial consumption for the sample. Unfortunately, peak demand levels as estimated by the model, increased by $12 \%$. This demand increase may be virtually eliminated if controls are calibrated properly.

Two of the buildings audited had a need for replacement of their HVAC equipment. The combination of electric-resistance heating along with an inefficient air-conditioner has the potential to waste a large amount of energy. Energy efficient heat pumps were recommended and predicted savings were $34,000 \mathrm{kWh}$, or $5 \%$ of initial consumption, and $19 \mathrm{~kW}$, or $9 \%$ of initial demand. A control system should be installed in conjunction with an electric heat pump in order to obtain the full benefits.

Often when several retrofits are installed in a building, some interaction between them may occur, with varying results. The combination of retrofits for each building resulted in slight increases in energy savings, due to small interactions. The total energy savings for the buildings sampled are $217,000 \mathrm{kWh}$, which is a $32 \%$ reduction in consumption. Similarly demand savings were almost $46 \mathrm{~kW}$, representing a $22 \%$ reduction in initial demand. 


\section{S.5 CONCLUSIONS}

A joint demonstration between Duke Power Company and ORNL examined potential energy conservation opportunities for small commercial buildings, $(<10,000$ sq. feet). Duke Power supplied a significant amount of consumption information for over sixty small commercial customers. ORNL analyzed this data, and using monthly indices, targeted six buildings for site visits and subsequent retrofit recommendation.

Monthly, hourly, and audit data were used in energy simulation models to determine energy and demand savings associated with various retrofits. These included lighting, control and HVAC retrofits. Control retrofits using programmable thermostats, were predicted to save the most energy, with a $23 \%$ reduction in consumption. Lighting retrofits, which replaced inefficient incandescent and fluorescent fixtures with efficient fluorescent fixtures, saved approximately $11 \%$ of original consumption, with an $8 \%$ demand reduction. Replacement of older inefficient HVAC equipment with efficient heat pumps saved nearly $5 \%$ of total energy and reduced demand levels by $9 \%$. Altogether, if all retrofits were installed, savings are estimated at $32 \%$ and $22 \%$ of original consumption and demand.

When selecting retrofits for installation, several factors should be considered. A building with inefficient electric resistance heat will not recognize the same energy and demand savings from a lighting retrofit as seen with a building using an efficient heat pump This is due to the increase in heating system demand brought on by the reduction in the heat provided by the original lights. Utilities that favor lighting programs for their peak shaving potential and ease in installation and operation, should be aware of this caveat. HVAC controls, in this study, are the most successful retrofit for reducing energy consumption. This retrofit is often less attractive to utility interests as it's peak shaving capacity is usually negligible. Although consumers may initially find an automated system difficult to operate, the energy savings benefits are definitely 
worthwhile. All of these issues were confronted during the analysis of energy conservation opportunities in the buildings studied.

\section{Energy Conservation Opportunities in Small Commercial Buildings}

M. M. Abraham

J. M. MacDonald

ABSTRACT

As part of a joint project between Duke Power Co. and Oak Ridge National Laboratory (ORNL), a study was performed to determine the energy savings potential of small commercial buildings, located in the Duke Power service territory. This relatively untouched portion of the commercial sector has the potential for reducing energy consumption by $13 \%-25 \%$, which corresponds to a reduction in average annual operating costs of $\$ 500-\$ 1,000$ per building. A database of over sixty customers was used to target five buildings with unusually high levels of energy consumption and/or peak demand. Conservation measures in these buildings were selected on the basis of cost-effectiveness and relative non-intrusiveness on the occupants.

Together, ORNL and Duke Power representatives worked on data analysis, site-audits, and measure recommendations. Duke Power supplied hourly and monthly utility data, customer survey information and participated in site-audits. ORNL analyzed the data, developed targeting indices, performed site-audits and corresponding first-order energy simulations on candidate buildings, and recommended individualized conservation retrofits. For the five buildings examined, retrofits including lighting, controls, and HVAC systems accounted for a total reduction in consumption of $32 \%$, and in peak demand of $22 \%$. In addition, the study emphasizes the importance of continuous attention to the operating conditions of HVAC equipment and controls, in order to ensure long-term sustainability of these energy savings. 


\section{INTRODUCTION}

Duke Power Company is interested in understanding the customer and utility benefits of potential demand side management (DSM) measures for small commercial facilities in their service territory (North Carolina). The Existing Buildings Research Program of the U.S. Department of Energy (DOE), through DOE's Oak Ridge National Laboratory (ORNL), is interested in examining small commercial buildings to determine the highest level of savings that can be obtained for a reasonable cost. DOE agreed to provide technical support through ORNL for development and testing of a joint project with Duke Power on small commercial buildings to study these factors of interest.

The small commercial business sector has unique needs for assistance in implementing energy conservation measures. While larger businesses often have staff dedicated to the problem of energy conservation and sufficient capital to invest in such projects, smaller businesses usually have neither. National data (EIA 1994) indicate a trend toward fewer energy conservation features installed in smaller buildings (Figure 1.1). The data in Figure 1.1 must be viewed with some caution. The trend toward fewer measures in smaller buildings is definite and should be valid, but the extent of installation of measures in each building class may be much

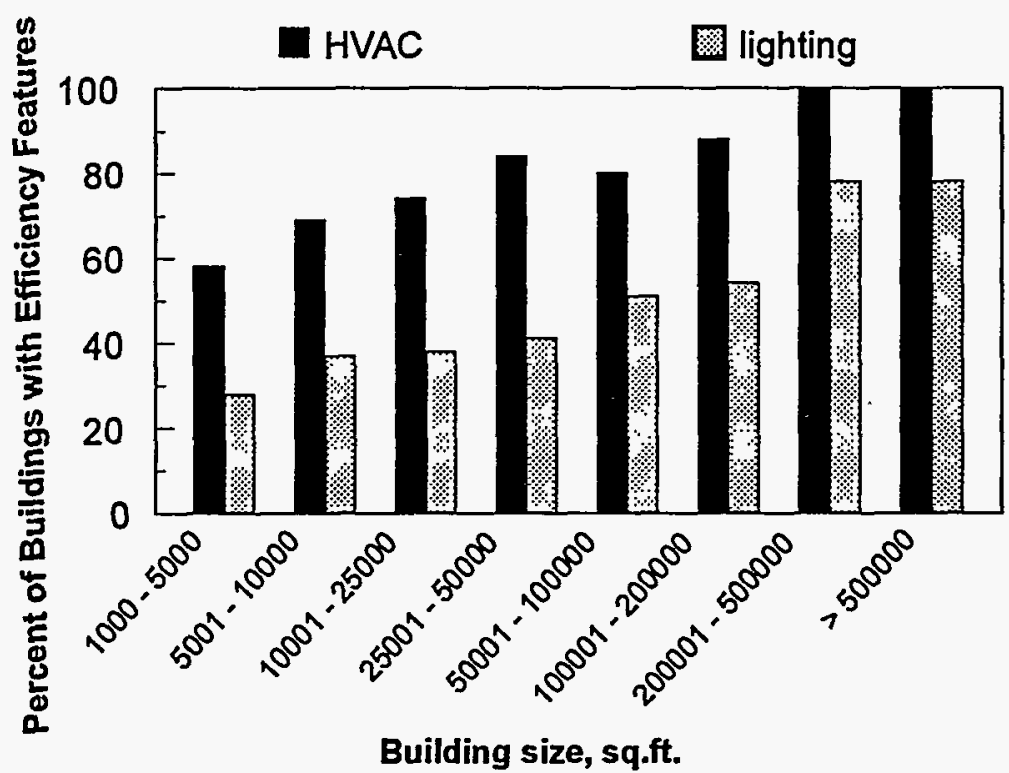

Figure 1.1 Percent of buildings with efficiency features, by floor area 
less than the percentage values might indicate, since the data depend on answers obtained during an interview of a building manager, operator, or occupant.

Electric utilities are in a good position to offer such services. Many utilities already extend programs to the small business customer, but most of these programs lack the incentives needed to induce widespread participation by the businesses. Private companies, such as Energy Service Companies (ESCOs) typically cannot provide services to small businesses due to the small scale of the individual buildings. Thus, small businesses have more need of energy assistance, fewer resources available to increase energy efficiency, and significant national potential for energy savings (Figure 1.1).

Previous work at Oak Ridge National Laboratory (ORNL) has indicated that energy and cost savings from energy conservation in the small commercial business sector can be substantial. In 1992 the U.S. commercial building sector consumed a little over 13 quads of primary energy, including electrical generation and distribution losses (OBT 1994, Table 1.3.1). This energy use results in slightly over $\mathbf{2 0 0}$ million metric tons of carbon emissions in the form of carbon dioxide (OBT 1994, Table 3.1.1). Estimates of achievable energy savings in this sector range from $13 \%$ to $25 \%$ (MacDonald 1986). Because the commercial sector accounts for $15 \%$ of all energy consumed and $31 \%$ of all electricity used in the United States (OBT 1994, Tables 1.1.2 and 1.1.3), achieving energy savings in this sector is important if international environmental emissions goals are to be addressed.

About three-fourths (over 3.5 million) of commercial buildings are estimated to have floor areas less than 10,000 square feet, accounting for about $22 \%$ of total commercial building floor area (EIA 1994). They consume approximately one fifth of the energy and account for almost $30 \%$ of the energy expenditures of the commercial sector (about 2.6 quads of primary energy at a cost of about $\$ 20$ billion in 1989) (EIA 1992). If the fraction of potential savings to total consumption is the same for small buildings as is estimated for the commercial sector as a whole, $13-25 \%$, potential energy savings from improved efficiency may be worth $\$ 2$ - $\$ 3$ billion 
per year in reduced operating costs for small businesses. The savings for a typical small building would be $\$ 500$ - $\$ 1,000$ per year.

\subsection{BACKGROUND}

Most electric utility building energy efficiency programs require participants to accept some responsibility for supervising or arranging installation of energy efficiency measures. ,However, small businesses often have difficulty accepting direct responsibility for deciding which energy conservation measures to implement, supervising the installation, and arranging favorable financing of the project. Better serving this sector probably requires that some assistance with these types of services be made available.

Some streamlining of the overall process of selecting and installing measures is needed because often the occupants and/or owners of smaller commercial buildings lack the financial ability to undertake the effort involved in the individualized selection of appropriate measures. The purpose of this study was to examine issues related to identification and selection of appropriate buildings and measures in the commercial sector. The study found that the buildings studied were all candidates for similar retrofits. Since a majority of potential savings is associated with these conservation opportunities, streamlined procedures for identification and quantification could be developed from these results.

\subsection{OBJECTIVE AND SCOPE}

The objective of this study is to determine the potential customer and utility benefits, including energy savings and demand reduction, for a range of energy efficiency measures in small commercial buildings in the Southeastern United States. The study also examines issues involved in obtaining field data for energy audits of small buildings. Activities related to 
screening energy use of buildings before site visits, field verification of building data, and validity of perceptions of building occupants are also examined.

The potential energy savings from typical measures are calculated for five buildings using the DOE-2.1D simulation program. This analytical estimation of savings is combined with the electric rate schedules, knowledge gained from site energy audits, and interviews of building occupants, to present a picture of factors affecting the potential for electrical energy, demand, and cost savings in these buildings. Specific implementation costs for selected retrofits were considered to be situation-dependent and thus a detailed cost analysis was beyond the scope of this study.

\subsection{REPORT ORGANIZATION}

The report is organized in seven sections. Section 1, the introduction, provides background information and defines the objective of the study. Section 2 discusses the targeting methods used to select the demonstration sites and explains the utility rate schedules. Sections 3 and 4 present the field inspection data and examples of the energy use data. The results of the simulation analysis, which include retrofit consumption and demand savings, are presented in Section 5. A discussion of recommendations and overall conclusions are found in Section 6.

\section{PRELIMINARY ANALYSIS}

\subsection{SELECTION OF INITIAL SAMPLE}

The buildings examined in the small commercial project were selected from an original list of over 60 candidates, which was supplied by Duke Power. This initial list included retail stores, offices, daycare centers and restaurants, all with less than 10,000 square feet of floor space. Using averaged monthly consumption, demand, and load indices ORNL was able to 
select thirteen candidates for further study. These choices were then reviewed by both parties and six buildings were selected for site audit, (performed by an ORNL/Duke Power team), and a corresponding retrofit analysis, (performed by ORNL).

\subsection{ENERGY CONSUMPTION, DEMAND, AND LOAD INDICES}

The buildings used for this demonstration were selected based on analysis of monthly energy consumption, demand, and load indices. These energy use indices, or EUl's, have been found to be a simplistic yet effective means of quickly analyzing building consumption and use of installed capacity (Haberl 1989). In addition to readily available monthly utility bill data, building floor area and operating hours are the only additional data required. Table 2.1 summarizes the expressions for these indices.

Table 2.1 Monthly energy use indices used to target demonstration buildings

\begin{tabular}{|c|c|c|c||}
\hline Index & Units & Expression & Use \\
\hline $\begin{array}{c}\text { Energy } \\
\text { Consumption }\end{array}$ & $\mathrm{W} / \mathrm{ft}^{2}$ & $\mathrm{EC}=\frac{\mathrm{kwh}}{\text { Total Hrs./mo. } \times \mathrm{ft}^{2}}$ & Consumption Level \\
\hline Demand & $\mathrm{W} / \mathrm{ft}^{2}$ & $\mathrm{D}=\frac{\mathrm{kW}}{\mathrm{ft}^{2}}$ & Demand Level \\
\hline $\begin{array}{c}\text { Electrical Load } \\
\text { Factor }\end{array}$ & none & $\mathrm{ELF}=\frac{\mathrm{kwh}(\mathrm{month})}{\mathrm{kW} \text { (peak) } \times \text { Total Hrs./mo. }}$ & Capacity Use \\
\hline $\begin{array}{c}\text { Occupancy Load } \\
\text { Factor }\end{array}$ & none & $\mathrm{OLF}=\frac{\mathrm{kwh}(\mathrm{month})}{\mathrm{kW} \text { (peak) } \times \text { Op. Hrs./mo. }}$ & After-Hour Consumption \\
\hline
\end{tabular}

Energy and demand indices are used to compare the consumption and demand levels with those of buildings of similar size and function. Both of these indices are expressed in terms of $\mathrm{W} / \mathrm{ft}^{2}$. Average consumption levels for small commercial buildings fall between 2 and $3 \mathrm{~W} / \mathrm{ft}^{2}$, 
while upper levels exceed $3 \mathrm{~W} / \mathrm{ft}^{2}$. Average demand levels for commercial buildings are between 5 and $7 \mathrm{~W} / \mathrm{ft}^{2}$ and high levels of demand are above $7 \mathrm{~W} / \mathrm{ft}^{2}$.

The electrical and occupancy load factors, ELF and OLF, are used to gain closer insight into the energy consumption patterns of the customer. The ELF helps target problems with unnecessary demand spikes. Smaller ELF's $(<0.25)$ are indicators of 'spikey' profiles during which building equipment may exhibit short-lived, high demand peaks. An example of this may occur during heat pump start up, if electric-resistance supplement heat is used. The OLF is a measure of the amount of after-hour consumption that occurs in the building. When the OLF nears 1.0 , or greater, equipment may be operating excessively during hours when the building is unoccupied.

Next, the list of over 60 candidates was reduced down to thirteen which were thought to be ideal demonstration sites. By using graphical box-plots, a years' worth of indices can be easily examined on a building-by-building basis. Figures 2.1 through 2.4 present the pre-audit box-plots of these indices." Additionally, limitations on indices, as discussed above, are labeled on the plots. It is important to note here that the floor areas and operating hours used were taken from a customer survey supplied by Duke Power. However, during site visits, many of these floor areas were found to be inaccurate and generally undersized.

From the sample of thirteen buildings, six were chosen for demonstration based on the annual profile of their EUl's, as shown in the box plots. Buildings with EUl's that fell above or below the warning ranges for each index, for a majority of the year, were considered to be ideal for retrofit. The six buildings included a clothing store, a liquor store, two restaurants, a day-care center and a small bank.

\footnotetext{
- Box-plots are used to display the distribution and mean of the data. The lower edge of the box represents the 25th percentile of the data, while the upper edge is the 75th percentile. The dotted 'tails' indicate data located above and below these percentiles. The horizontal dotted line inside the box represents the median or 50 th percentile and the cross signifies the average value of the data.
} 


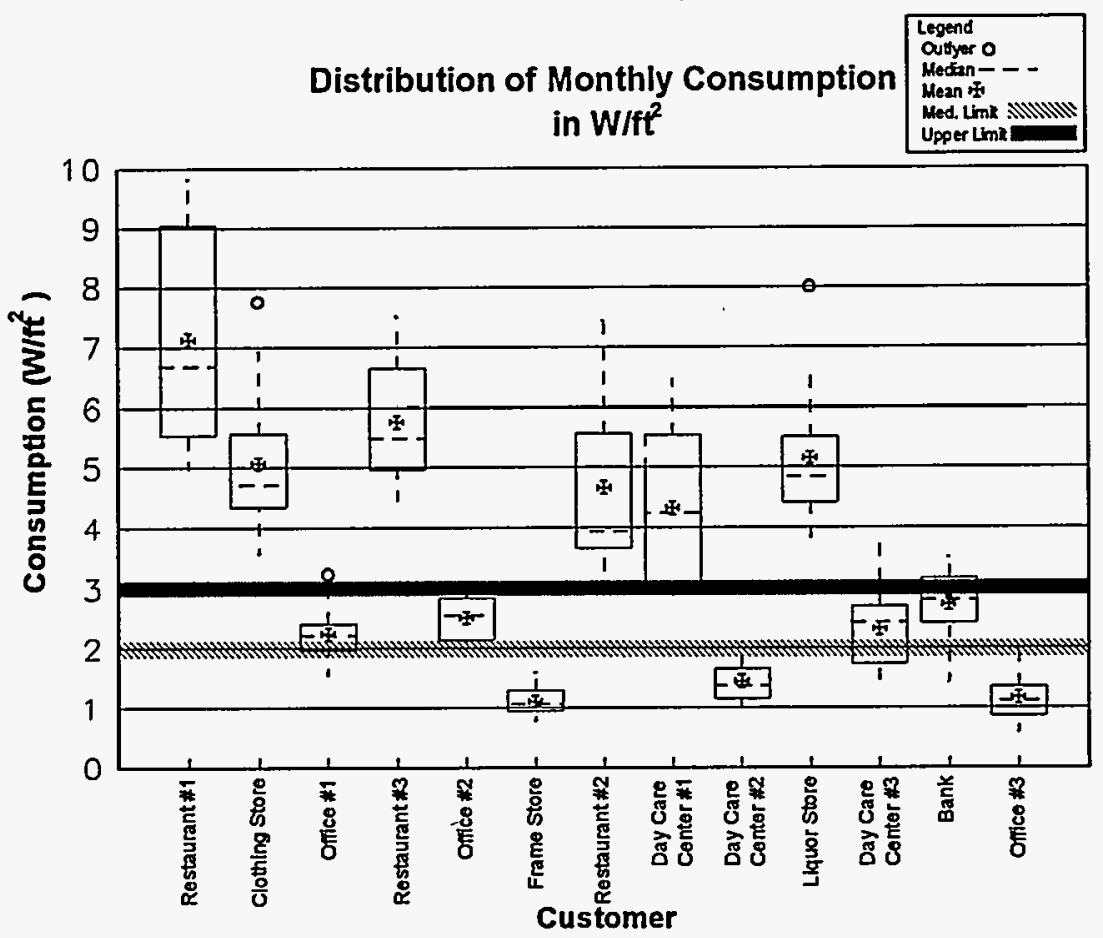

Figure 2.1 Distribution of Monthly Consumption, in W/ft ${ }^{2}$, for candidate buildings

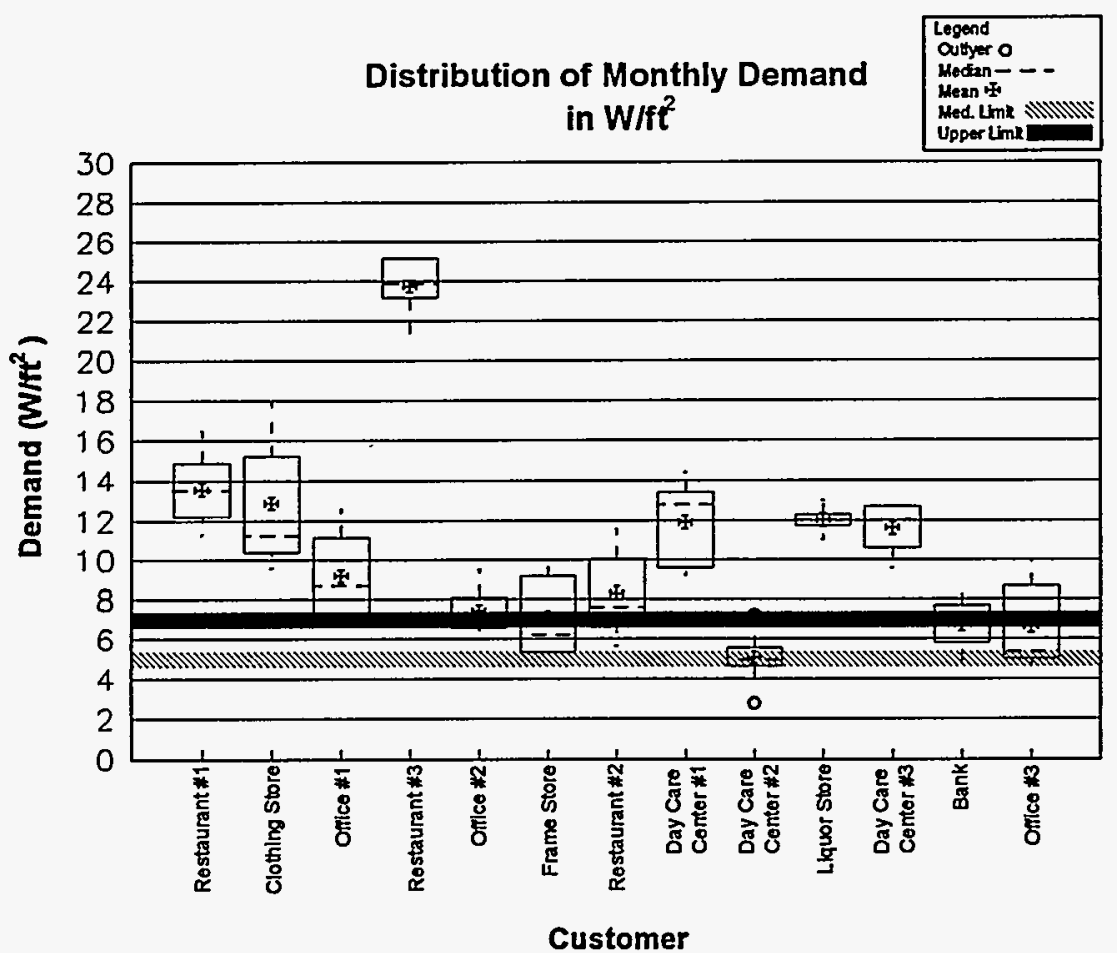

Figure 2.2 Distribution of Monthly Demand, in W/ft ${ }^{2}$, for candidate buildings 


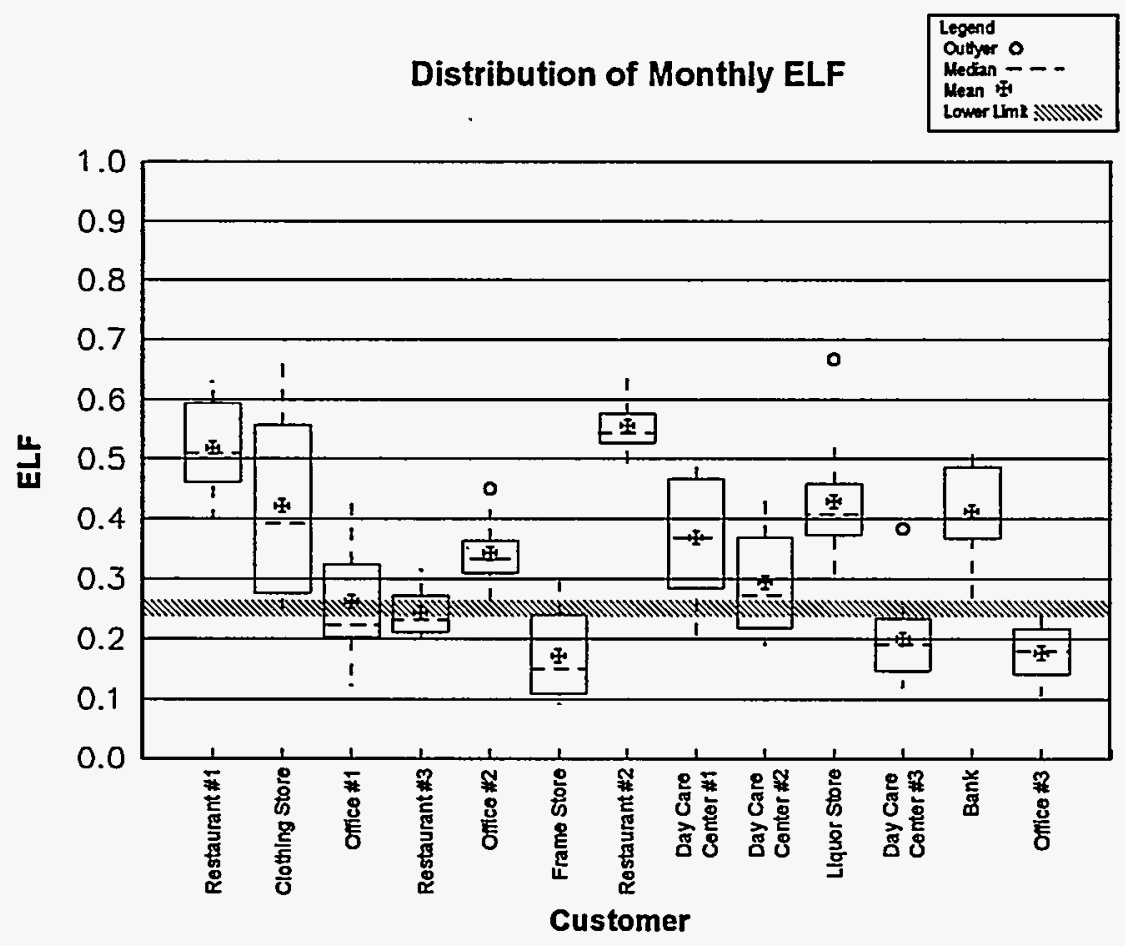

Figure 2.3 Distribution of Monthly ELF's for candidate buildings

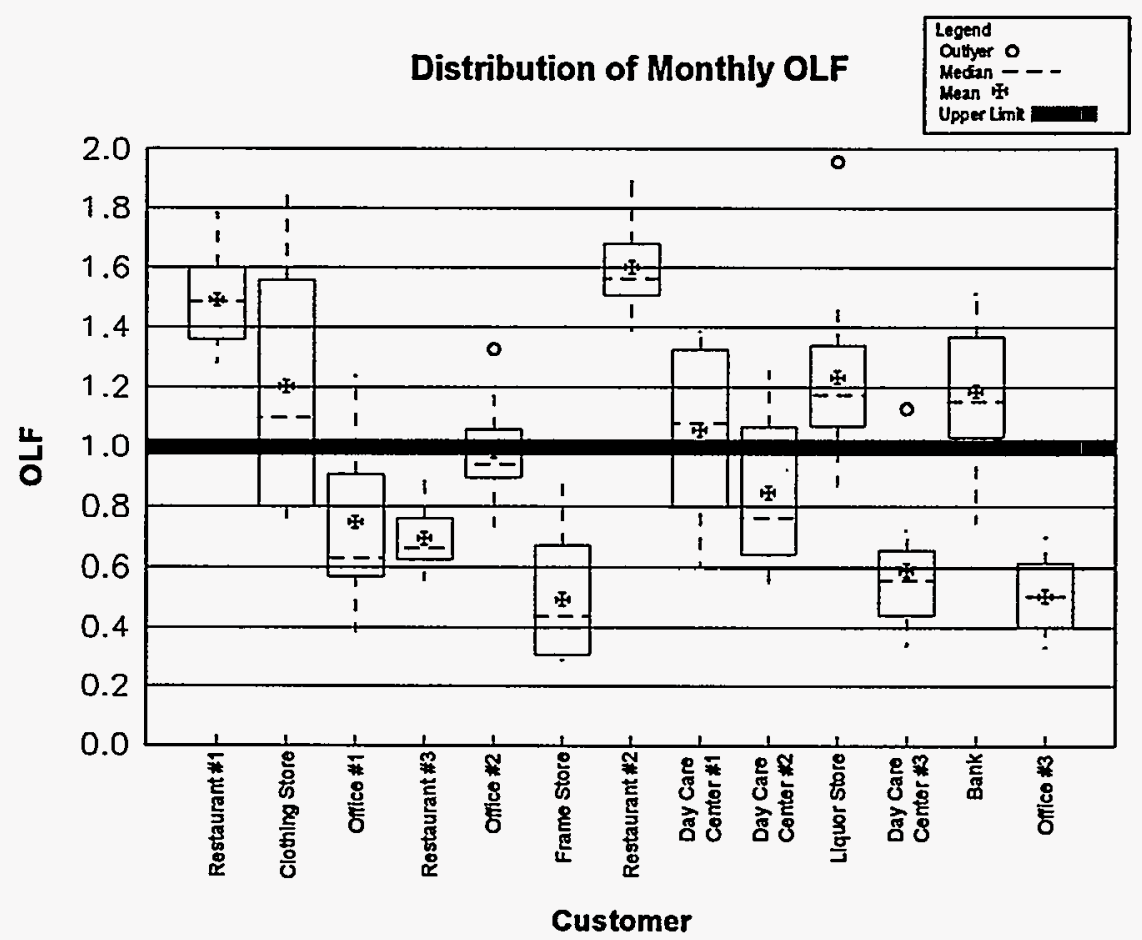

Figure 2.4 Distribution of Monthly OLF's, for candidate buildings 


\subsection{RATE SCHEDULES}

Over the six buildings selected, three different rate schedules were employed. The restaurants were on a time-of-use schedule while the other buildings had general service contracts. The time-of-use schedule is Duke Power's OPT structure and the general service schedules were GA and $G$. The schedules used in this study were made effective on July 1 , 1993 and subsequent changes are not included. Retrofit cost-saving estimates are based on these costs. A brief description of each structure is given below.

Duke Power Co. Schedule GA: General Service (Duke Power 1993a.). The GA cost structure is made up of a facility charge, base demand charge, and consumption charges. The consumption costs are varied based on the customers 'peak demand' and are referred to as an expandable block structure. Peak demand is defined as the largest of the following:

1. The maximum integrated thirty-minute demand in the previous 12 months

2. Fifty percent of the contract demand

3. $15 \mathrm{~kW}$

The GA schedule is seasonal, with higher energy costs applied during the months of April through November. Fuel charges are included in the rates, and penalties for power factors below $85 \%$ are included as an additional charge. Figure 2.5 illustrates the GA rate structure.

Duke Power Co. Schedule G. General Service (Duke Power 1993b.) The schedule G cost structure is identical to that of schedule GA with one exception: there are no seasonal changes in costs. The base facility and demand charges are the same, while year-round energy charges are equivalent to the months of April through November on the GA schedule. Peak demand is calculated similarly to GA service, and power factor penalties also apply. Figure 2.5 includes the $G$ structure in the rate description. 


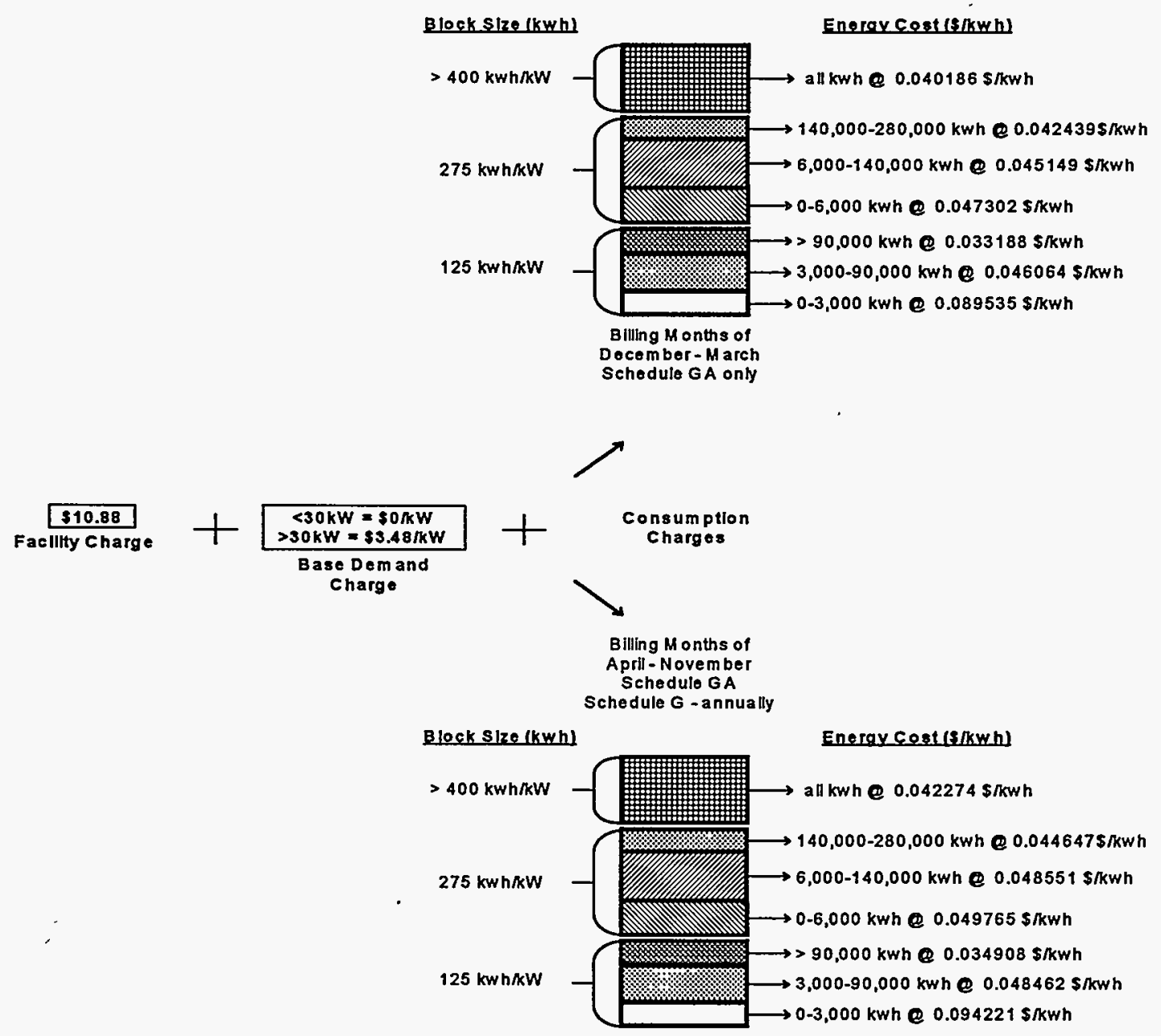

Figure 2.5 Duke Power schedules GA and G, effective July 1, 1993

Duke Power Co. Schedule OPT (Duke Power 1993c.) The OPT rate schedule has a time-of-day rate structure. On-peak hours and other details are given in Figure 2.6. The onpeak demand is defined as the largest of the following:

1. The maximum integrated thirty-minute demand during the on-peak period for the billing month

2. Fifty percent of the Contract Demand, or $50 \%$ of the On-Peak Contract Demand

3. $15 \mathrm{~kW}$

The off-peak, or economy demand is determined by comparing the largest of :

1. The maximum integrated thirty-minute demand during the present month

2. Fifty percent of the contract demand 
with the on-peak billing demand. If the on-peak billing demand is smaller than the maximum of 1. or 2., then the economy demand is taken as the difference between these two. On-peak demand costs during the months of June through September are nearly twice as much as those during the rest of the year. Similarly, on-peak energy consumption costs twice as much, at $0.043246 \$ / \mathrm{kWh}$, than off-peak consumption. Fuel costs are included in the energy charges and power factor levels below $85 \%$ are penalized.

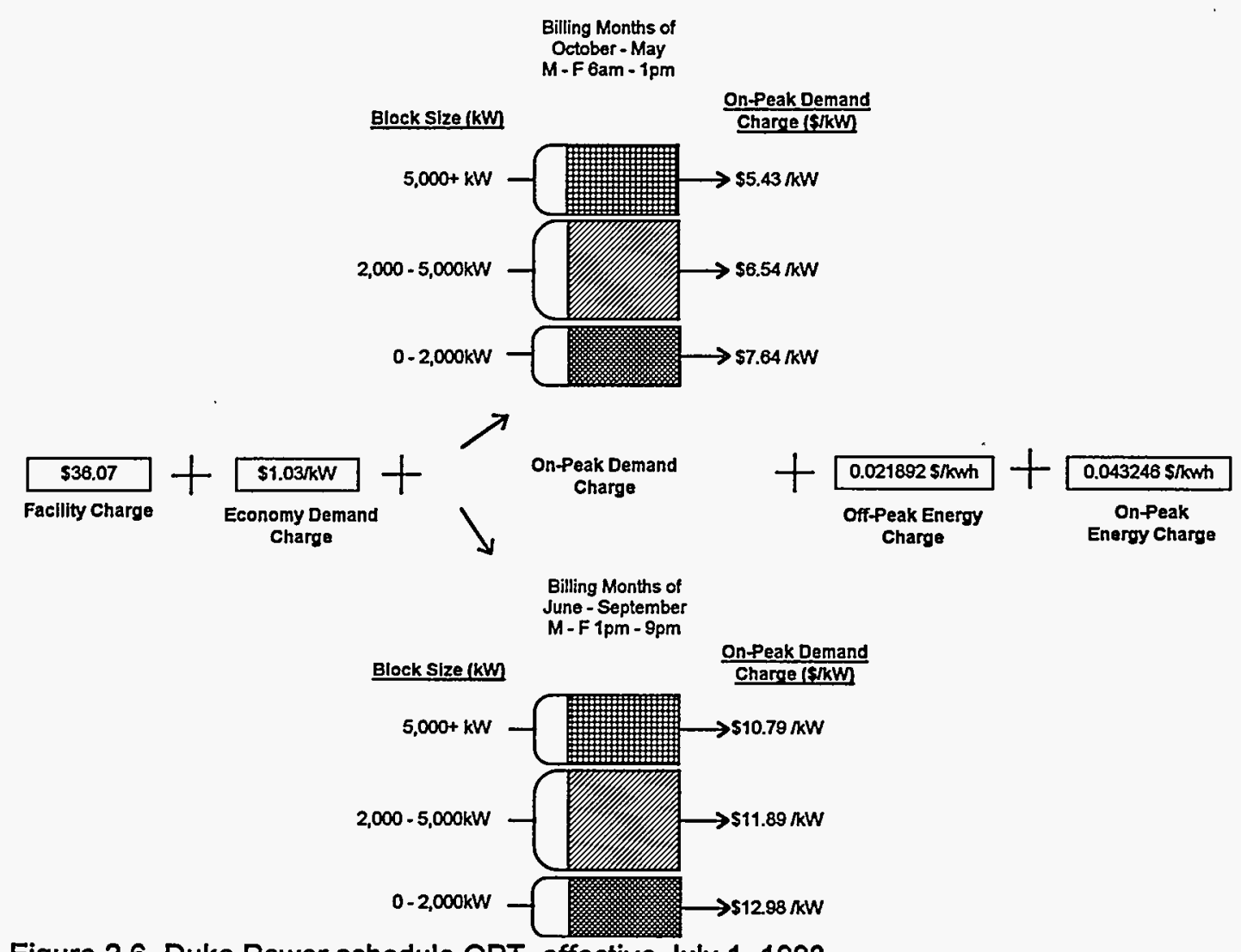

Figure 2.6 Duke Power schedule OPT, effective July 1, 1993

\subsection{BUILDING INFORMATION}

Table 2.2 lists the buildings which were selected along with pertinent characteristic information and utility billing data from September 1992 through August 1993. Duke Power made arrangements with these customers for site audits to be performed in early June, 1994. 


\begin{tabular}{|c|c|c|c|c|c|c|}
\hline Name & Function & Floor Area & Rate Schedule & $\begin{array}{c}\text { Annual Peak } \\
\text { kW }\end{array}$ & $\begin{array}{l}\text { Annual } \\
\mathrm{kWh} \\
\end{array}$ & $\begin{array}{c}\text { Annual Utility } \\
\text { Costs }\end{array}$ \\
\hline Restaurant \#1 & Restaurant & $6,370 \mathrm{ft}^{2}$ & OPT & 78 & 303,400 & $\$ 16,075$ \\
\hline Clothing Store & Retail & $3,150 \mathrm{ft}^{2}$ & GA & 45 & 129,171 & $\$ 8,100$ \\
\hline Day Care Center \#1 & Day Care & $4,000 \mathrm{ft}^{2}$ & GA & 33 & 96,320 & $\$ 6,330$ \\
\hline Restaurant \#2 & Restaurant & $4,420 \mathrm{ft}^{2}$ & OPT & 65 & 227,900 & $\$ 12,200$ \\
\hline Liquor Store & Retail & $2,800 \mathrm{ft}^{2}$ & GA & 21 & 73,861 & $\$ 5,704$ \\
\hline Bank & Bank & $3,700 \mathrm{ft}^{2}$ & $\mathbf{G}$ & 35 & 79,680 & $\$ 5,396$ \\
\hline
\end{tabular}

Table 2.2 Buildings selected for ORNL/Duke Power small commercial demonstration

\section{FIELD INSPECTION}

The scheduled site audits of the six buildings were performed in two days by a team of two ORNL engineers and one Duke Power representative. The information gathered for each building was recorded using a standard audit format, supplied by ORNL, (MacDonald 1989). Visits began with a tour given by the buildings' representative, usually a daytime manager. After the tour, the customer was interviewed to determine operating hours and general building usage/background. All of the customers seemed to be somewhat interested in understanding the energy use in their respective buildings. Auditors then checked lighting levels, identified and quantified installed lighting capacity, located and evaluated HVAC equipment and controls, noted additional sizable equipment, and verified floor areas. When comparing floor areas with those obtained from Duke Power customers surveys, most of the buildings audited had significantly larger floor areas than had been previously indicated. Key data are presented for each building in Tables 3.1 through 3.6. 


\subsection{FIELD INSPECTION DATA}

Restaurant \#1 Several interesting conservation opportunities exist for this freestanding building. All of the meat is prepared on a large pit-grill, fueled by wood, which is located adjacent to the air-conditioned dining areas. The grill has a large exhaust hood which removes a great deal of conditioned air from the building. Six standard bi-metal coil thermostats control the heating and air-conditioning systems. Thermostats located in the dining areas were not secured and were actually adjusted by customers and staff. The restaurants' representative estimated heating and cooling set points to be around $72^{\circ} \mathrm{F}$, with no real implementation of a night setback.

\begin{tabular}{||l|l||}
\hline Name & Restaurant \#1 \\
\hline Floor Area $\left(\mathrm{ft}^{2}\right)$ & 6,370 \\
\hline Op. Hours $/$ Week & 91 \\
\hline & \\
Lighting Type & 40 W Fluorescent., 75W Incand. \\
\hline Lighting Capacity & 10.05 kW \\
\hline HVAC Controls & Standard Thermostat \\
\hline & \\
Air-Conditioning & $(5)$ - 4 Ton units \\
\hline & \\
\hline Heating & Gas \\
\hline Additional Equipment & Food Preparation/Appliances \\
\hline
\end{tabular}

Table 3.1 Site audit information for Restaurant \#1

Dining area lighting was strictly recessed incandescent, with a capacity of nearly $1.5 \mathrm{~W} / \mathrm{ft}^{2}$. Illuminance in the dining area, however was low, ranging from 25 to 63 foot-candles, due to dark interior wall and ceiling surfaces. The kitchen and restrooms had 3 $\mathrm{kW}$ of $40 \mathrm{~W}$ fluorescent $\mathrm{T}-12$ lamps, for an approximate capacity of $2.2 \mathrm{~W} / \mathrm{ft}^{2}$.

While most of the cooking, other than meat, was done using gas, there were still several electrical appliances running. However, since specialized attention to restaurant equipment is beyond the requirements of streamlined audit procedures, focus was placed more on other building equipment.

Clothing Store The Clothing Store is located within a small enclosed strip mall. While the entrance is actually inside of the mall, the store front is totally glass and has significant exterior 
exposure. The space is cooled by two older air-conditioning units and heated with electricresistance heat. These units are controlled by standard manual thermostats. The store manager commented that, for security reasons, the HVAC system was shut-off at night however detailed

\begin{tabular}{||l|l||}
\hline Name & Clothing Store \\
\hline Floor Area ( $\mathrm{ft}^{2}$ ) & 3,150 \\
\hline & \\
Op. Hours/Week & 71 \\
\hline & \\
Lighting Type & $34 \mathrm{~W}$ Fluor., 75W \& 150W Incand. \\
\hline & \\
Lighting Capacity & $9.45 \mathrm{~kW}$ \\
\hline & \\
HVAC Controls & Standard Thermostat \\
\hline & \\
Air-Conditioning & 5 Ton, 4 Ton \\
\hline Heating & Electric Resistance \\
\hline Additional Equipment & None \\
\hline
\end{tabular}
energy data did not support this claim. She also felt that only one unit was cooling properly, and thus was primarily responsible for supplying most of the cold air. Regardless of the natural daylighting provided by the glazing in the store front, several large incandescent spotlights are left on during the daytime, unnecessarily. In fact, the store has a total of 3.5 $\mathrm{kW}$ of installed $75 \mathrm{~W}$ and $150 \mathrm{~W}$ incandescent spotlights. Fluorescent $34 \mathrm{~W} \mathrm{T-12}$ fixtures provide an additional capacity of $5.9 \mathrm{~kW}$ in the sales area. The manager noted that she must replace fluorescent lamps on a monthly basis. There is a possibility that the replacement lamps may not be compatible with the installed ballasts.

Day Care Center \#1 The representative at the Day Care Center told audit members that a lighting retrofit may have occurred sometime during the previous year. The lighting system was efficient, consisting of fixtures with 32 W T-8 fluorescent lamps and four-lamp electronic ballasts. The monthly utility data, however, did not reflect any significant decreases in energy within the previous 12 months.

The freestanding building is cooled by two 5 ton units and heated with electric-resistance heat. The controls for this system are provided by standard thermostats with no programmable 


\begin{tabular}{||l|l||}
\hline Name & Day Care Center \#1 \\
\hline Floor Area ( $\mathbf{f t}^{2}$ ) & 4,000 \\
\hline & 60 \\
\hline Op. Hours/Week & \\
\hline & 32 W Fluor.. 4 Lamp Elec. Ballasts \\
\hline Lighting Type & \\
\hline & $4.4 \mathrm{~kW}$ \\
\hline Lighting Capacity & Standard Thermostat \\
\hline HVAC Controls & (2)-5 Ton A/C \\
\hline Air-Conditioning & \\
\hline & Electric Resistance \\
\hline Heating & \\
\hline & Food Prep., Clothes Washer/Dryer \\
\hline
\end{tabular}

Table 3.3 Site audit information for Day Care Center \#1 capabilities. The representative claimed that thermostats were manually set back at night, however the monthly OLF's for the building were often above 1.0, indicating after-hour operation of equipment.

In addition to standard small commercial building equipment, the Day Care Center also had a small amount of food preparation and laundry equipment.

Restaurant \#2 Restaurant \#2 is cooled by two $71 / 2$ ton units and heated with gas heat. Programmable thermostats are used to control the HVAC system, and for the most part, were programmed correctly. However, since OLF's were close to 1.0 for several months, after-hour consumption takes place in some form. The bathrooms were found to be over-cooled and the

\begin{tabular}{||l|l||}
\hline Name & Restaurant \#2 \\
\hline Floor Area (ft ${ }^{2}$ ) & 4,420 \\
\hline & \\
Op. Hours Week & 95 \\
\hline & \\
Lighting Type & $11 \mathrm{~W}, 50 \mathrm{~W}, 60 \mathrm{~W}$ Fluorescents \\
\hline & $2.3 \mathrm{~kW}$ Dining, $\sim 1$ kW Outdoor \\
\hline Lighting Capacity & \\
\hline HVAC Controls & Smart Thermostat \\
\hline & \\
Air-Conditioning & $(2)-7.5$ Ton AVC \\
\hline Heating & Gas \\
\hline Additional Equipment & Food Prep., Appliances, Neon Signs \\
\hline
\end{tabular}

Table 3.4 Site audit information for Restaurant \#2 manager had mentioned that this was a problem.

The' dining area was lit with

$2.3 \mathrm{~kW}$ of various sizes of incandescent spotlights. Approximately 25 neon signs were also located in the dining areas. Exterior lighting is estimated to be slightly greater than $1 \mathrm{~kW}$. Most of the cooking equipment in the kitchen is gas heated. Additional electric 
appliances and refrigerators were also installed. The manager expressed interest in energy management since the utility costs cut into his reported profits.

Liquor Store The Liquor Store is located in a freestanding retail building and is owned and operated by the county. The building is cooled with a single 10 ton heat pump, which was recently installed to replace storm-damaged equipment. The system is controlled manually via standard thermostat. The representative complained of ventilation problems and large solar

\begin{tabular}{||l|l||}
\hline Name & Liquor Store \\
\hline Floor Area ( $\mathrm{ft}^{2}$ ) & 2,800 \\
\hline & \\
Op. Hours Week & 63 \\
\hline & \\
Lighting Type & $40 \mathrm{~W}, 75 \mathrm{~W}$ T-12 Fluorescents \\
\hline & \\
Lighting Capacity & $9.03 \mathrm{~kW}$ \\
\hline & \\
HVAC Controls & Standard Thermostat \\
\hline Air-Conditioning & 10 Ton Heat Pump \\
\hline Heating & Heat Pump \\
\hline Additional Equipment & Small Water-Heater \\
\hline \hline
\end{tabular}

Table 3.5 Site audit information for Liquor Store loads from the glass store front. He claimed that he regularly turns off the air-conditioning equipment at night but leaves the fans running. Once again, detailed energy data did not support this claim. Fans are probably switched from the 'auto' mode to the 'always on' mode, while the air-conditioning equipment still cycles.

The building has a very high illumination level. Retail and storage areas are lit with $\mathbf{4 0}$ W and 75 W T-12 fluorescents with magnetic ballasts. For the most part, the lights in the storage area are manually shut-off when unoccupied. Total lighting capacity is over $9 \mathrm{~kW}$, or $3.25 \mathrm{~W} / \mathrm{ft}^{2}$ and measured lighting levels in the sales area ranged from 120 to 130 foot-candles.

Bank The bank is located at the end of a small strip mall. The manager of this branch expressed a great deal of interest in energy conservation. He claimed that in the year that he had worked there, he had tried to implement manual setbacks on HVAC and lighting. However, monthly and hourly data did not reflect any noticeable changes in energy consumption during that time. The manager had just installed a new 9 ton heat pump, which supplies most of the 
office and teller areas. An additional 3-ton air-conditioner with electric-resistance heat supplies the drive-thru window area.

\begin{tabular}{||l|l||}
\hline Name & Bank \\
\hline Floor Area $\left(\mathrm{ft}^{2}\right)$ & 3,700 \\
\hline & \\
Op. Hours/Week & 41 \\
\hline Lighting Type & $40 \mathrm{~W} \mathrm{T-12}$ Fluor.,60W Incand. \\
\hline & \\
Lighting Capacity & $6.17 \mathrm{~kW}$ \\
\hline HVAC Controls & Standard Thermostat \\
\hline Air-Conditioning & 9 Ton Heat Pump, 3 Ton AVC \\
\hline Heating & Heat Pump \& Electric-Resistance \\
\hline Additional Equipment & Computers \\
\hline \hline
\end{tabular}

Offices and teller areas

were lit with over $5 \mathrm{~kW}$ of fluorescent fixtures with $40 \mathrm{~W}$ T-12 lamps and 2-lamp magnetic ballasts. Hall and office areas also had nearly $1 \mathrm{~kW}$ of $60 \mathrm{~W}$ incandescent spot lighting. Combining both fluorescent and incandescent fixtures, the bank has an installed lighting capacity of nearly $1.7 \mathrm{~W} / \mathrm{ft}^{2}$.

Table 3.6 Site audit information for the Bank

\subsection{SUMMARY}

Site visits to six small commercial buildings were performed in the beginning of June 1994 by an ORNL/Duke Power team. The floor areas in most of the buildings were found to be considerably greater than earlier recorded-which has an effect on some of the energy indices. The majority of buildings audited had inefficient lighting systems and HVAC control problems. A great deal of electric-resistance heating was also seen in these buildings. The audits verified what the indices and monthly data were saying: a great potential for energy conservation exists in this market. Most of the participants seemed eager to reduce energy consumption and to learn more about efficiency opportunities. 


\section{ENERGY USE DATA}

Prior to the audit trip, available data (July 1992 through July 1993) were analyzed to gain insight into the energy consumption and demand of the candidate buildings. Duke Power supplied ORNL with monthly utility bills and hourly sub-metered end-use data for this period. Duke Power also provided data taken from customer surveys which included operating hours, estimated floor areas and equipment capacities. A file for each building was developed which contained monthly energy use indices, monthly utility bill analysis including costs and consumption by rate schedule, and graphs of hourly end-use data for four months per year. Summaries of the data analysis were used by the audit team to aid in the inspection and to help auditors identify potential energy problems. Following the site visits, additional data were obtained from Duke Power covering the period of August 1993 through August 1994. A brief description of the data compiled for each building visited is given below. Note that all indices have been adjusted using the actual building gross floor areas measured during the on-site audit.

\subsection{ENERGY USE DATA ANALYSIS FOR RESTAURANT \#1}

\subsubsection{Monthly Data}

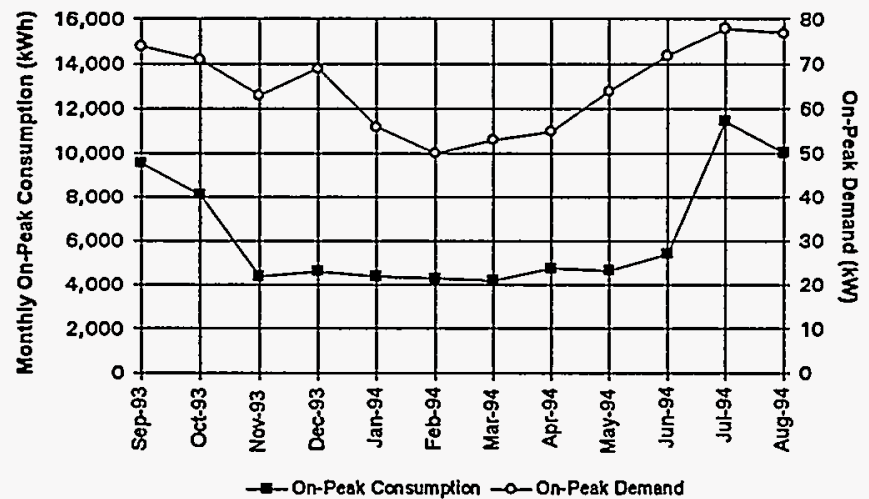

Figure 4.1 Monthly On-Peak Consumption and Demand for Restaurant \#1
Monthly

energy consumption and demand from utility bills are given in Figures 4.1 and 4.2. The data presented span from September 1993 through August 1994. Recall that the restaurant has a time-of-use contract, so on: and off-peak 
consumption and demand profiles are given. Total on-peak consumption for the year was $75,680 \mathrm{kWh}$ and off-peak consumption was $227,720 \mathrm{kWh}$, for a total of $303,400 \mathrm{kWh}$ annually. The peak demand recorded for this customer is $78 \mathrm{~kW}$ and total utility costs were $\$ 16,075$, or $\$ 2.50 / \mathrm{ft}^{2}$.

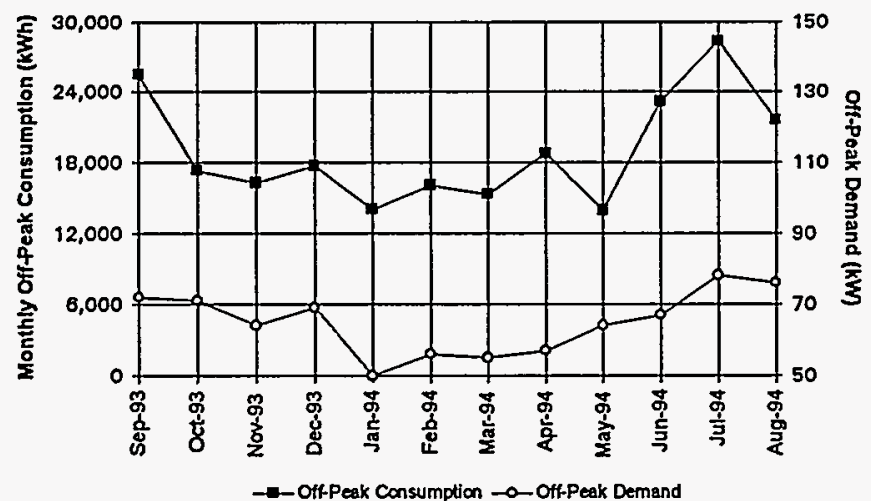

Figure 4.2 Monthly Off-Peak Consumption and Demand for Restaurant \#1

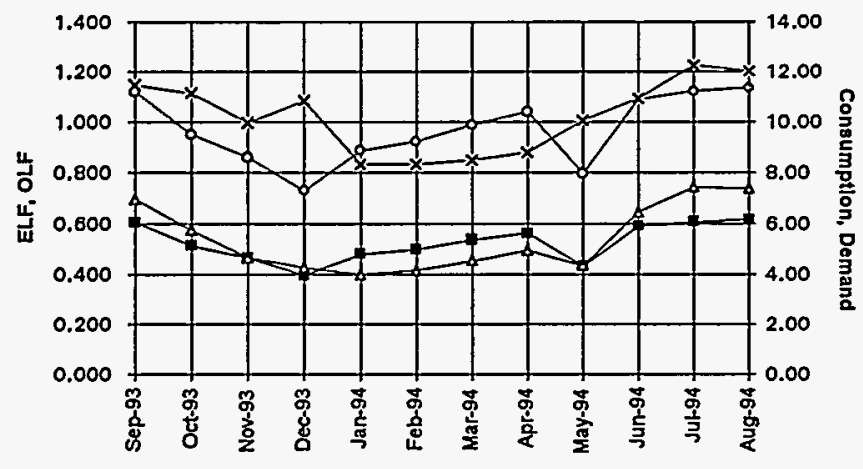

Figure 4.3 Monthly energy-use indices for Restaurant \#1
Figure 4.3 contains the monthly energy indices for the period of September 1993 through August 1994. Both consumption and demand indices are considerably higher than the allowable levels. The OLF's are almost consistently above the upper limit of 0.8 , while ELF's are above 0.4 . This combination of load factors indicates a definite a pattern of significant after-hour consumption. Although this building is a restaurant, with some amount of after-hour consumption expected, the level of consumption still appears to be quite high.

\subsubsection{Hourly Data}

End-use hourly data were also available for Restaurant \#1. This data spanned the same amount of time as the monthly meter data. Figures 4.4 (a) and (b) help illustrate the value of the hourly data, for two weeks in 1993. These figures were used to verify the problems with after- 
hour consumption, specifically by the air-conditioning equipment during summer months. There is a great deal of consumption which was not categorized but is probably made-up of lighting and electrical kitchen appliances.
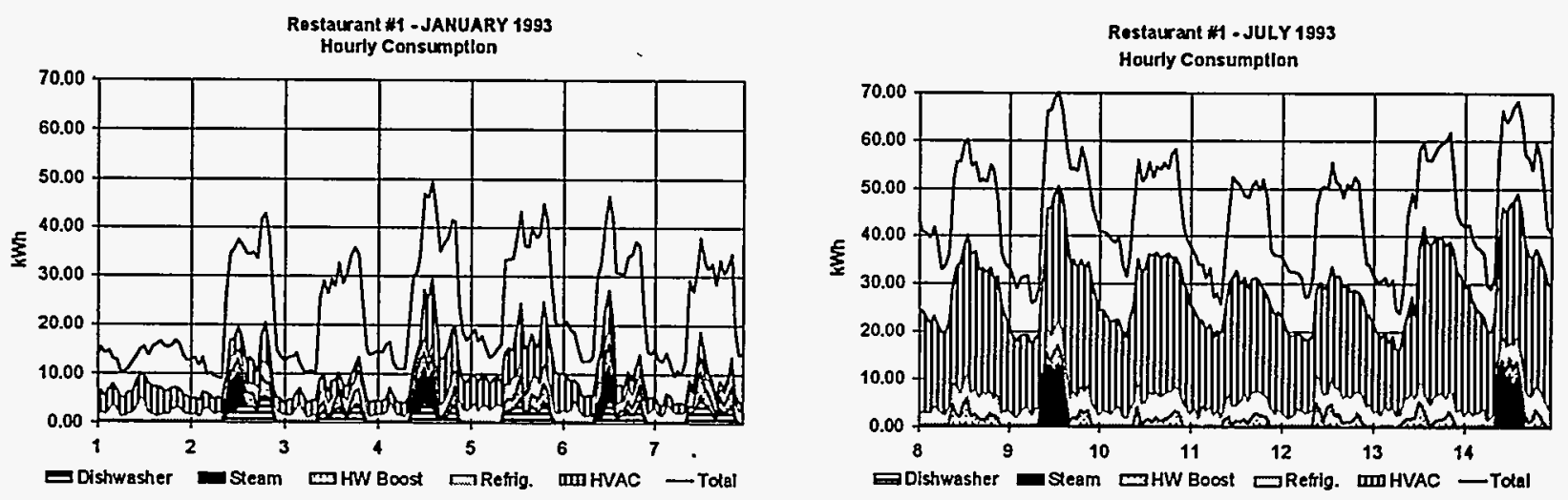

Figure 4.4 (a) Hourly end-use consumption, January $1-7,1993$ (b) Hourly end-use consumption, July 8 - 14, 1993, Restaurant \#1

\subsection{ENERGY USE DATA ANALYSIS FOR CLOTHING STORE}

\subsubsection{Monthly Data}

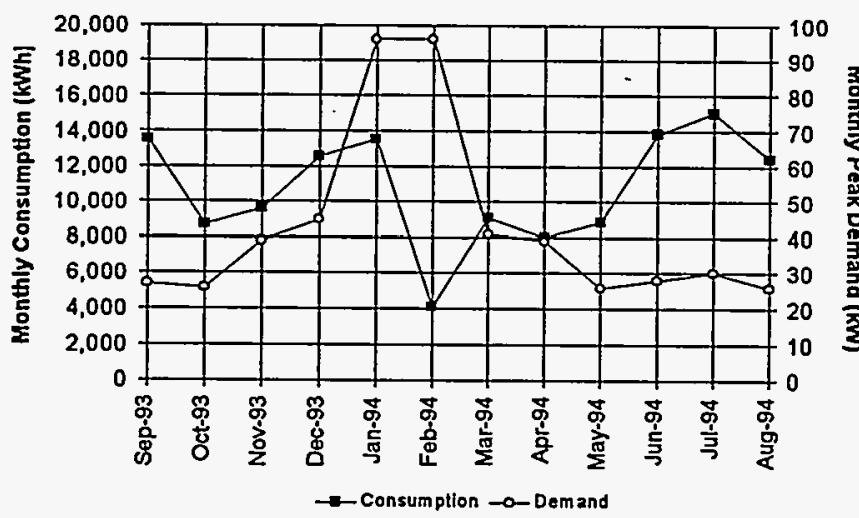

Figure 4.5 Monthly consumption and demand for Clothing Store
The monthly utility data, alone, for the Clothing Store from September 1993 through August 1994 unveil some interesting problems, (Figure 4.5). Large demand spikes of $96 \mathrm{~kW}$ were recorded during the months of January and February. 
Interestingly, though, consumption levels do not show corresponding behavior. In fact, consumption drops by nearly $10,000 \mathrm{kWh}$ from January to February. Annual consumption for the period is $129,000 \mathrm{kWh}$ and corresponding utility costs are $\$ 8,200$, or $\$ 2.60 / \mathrm{ft}^{2}$.

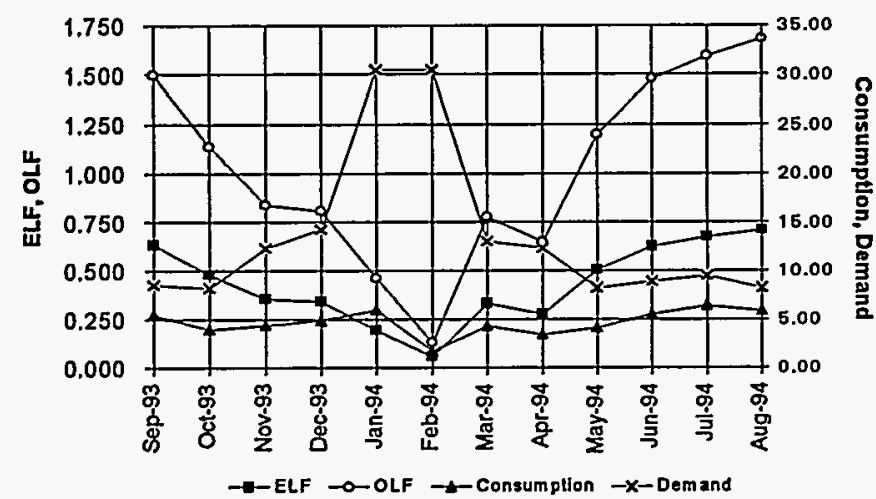

Figure 4.6 Monthly energy indices for Clothing Store Monthly energy indices support the potential problems seen in the utility data (Figure 4.6). Consumption indices are above 3.0 $\mathrm{W} / \mathrm{ft}^{2}$ for the majority of the year, excluding February, which drops to $1.69 \mathrm{~W} / \mathrm{ft}^{2}$. Demand indices are well above the screening limit of 7.0 $\mathrm{W} / \mathrm{ft}^{2}$, reaching as high as $30 \mathrm{~W} / \mathrm{ft}^{2}$ during January and February, 1994. Correspondingly, the ELF for February drops to 0.055 , reflecting the large demand spike that occurs during that month. OLF's are greater than 0.8 for most of the year as equipment is operated during unoccupied hours.

\subsubsection{Hourly Data}

Hourly consumption profiles for a week in January 1993 and for a week in July 1993 are given in Figures 4.7 (a) and (b). While lights are regularly shut-off at night, the HVAC system is somewhat unregulated. A large amount of after-hour consumption exists, especially during summer months. This data also refutes the manager's claim that heating/cooling equipment is off at night. The jagged profile experienced in January is characteristic of a building which uses electric-resistance heat, in some form. Had a heat pump been installed, with supplemental heating programmed properly, the heating consumption profile would be similar to the step-wise air-conditioning profile seen during July. 
Hourly data for the months of January and February 1994 were consulted to determine what was causing the large demand spikes in the utility bill. These large spikes, however, did not show up in the hourly data, leading to the conclusion that either an error was made in the utility bill or the peaks occurred within the utility's 30-minute demand interval but were not detected by the hourly data.

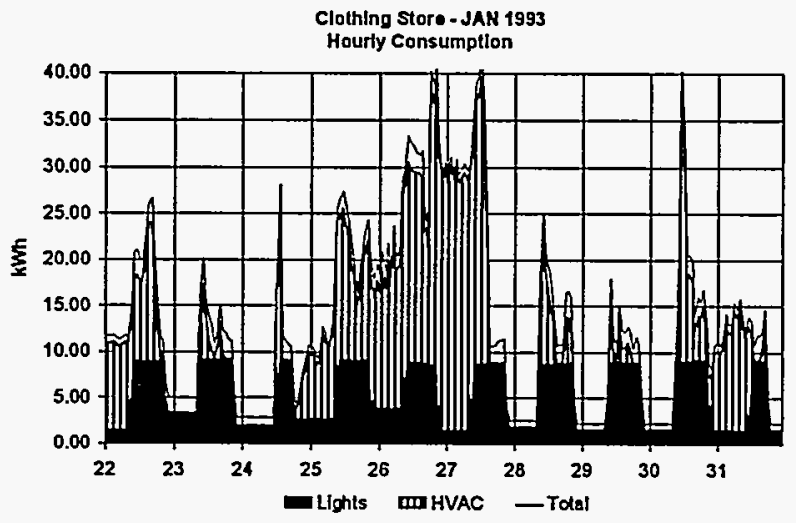

Figure 4.7 (a) Hourly end-use consumption, January consumption, July $1-7,1993$, Clothing Store

\subsection{ENERGY USE DATA FOR DAY CARE CENTER \#1}

\subsubsection{Monthly Data}

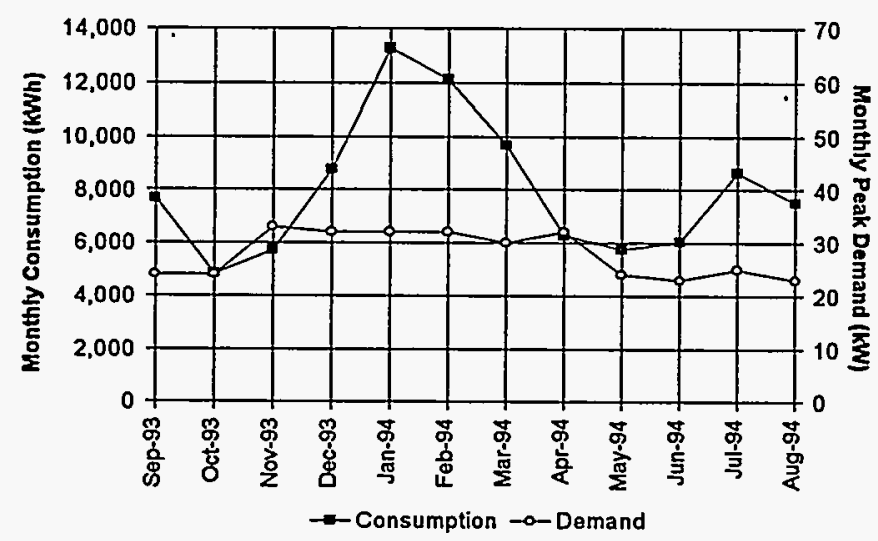

Figure 4.8 Monthly consumption and demand for Day Care Center \#1

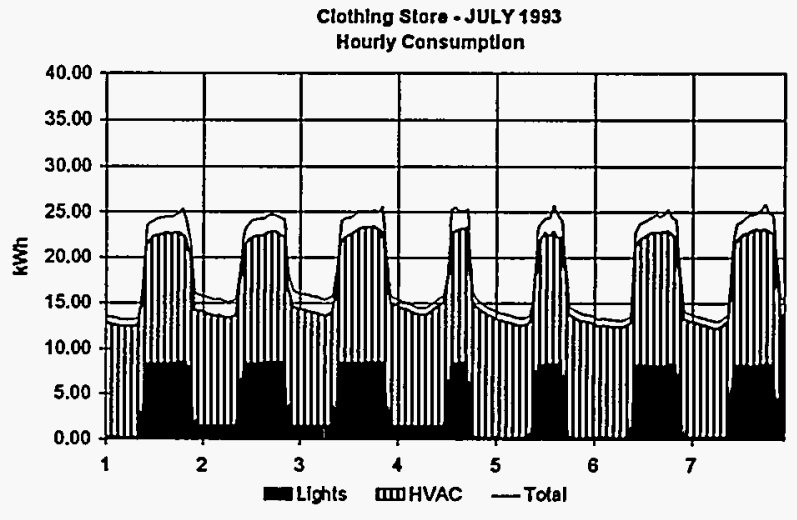
$22-31,1993$ (b) Hourly end-use

(1)

$$
\text { (1) }
$$


consumption profile is definitely seasonal, with higher consumption occurring during the colder months of the year. Similarly, peak demand kW jump from the mid-20's to low-30's during the colder months. These profiles reflect the building's reliance on electric-resistance heat.

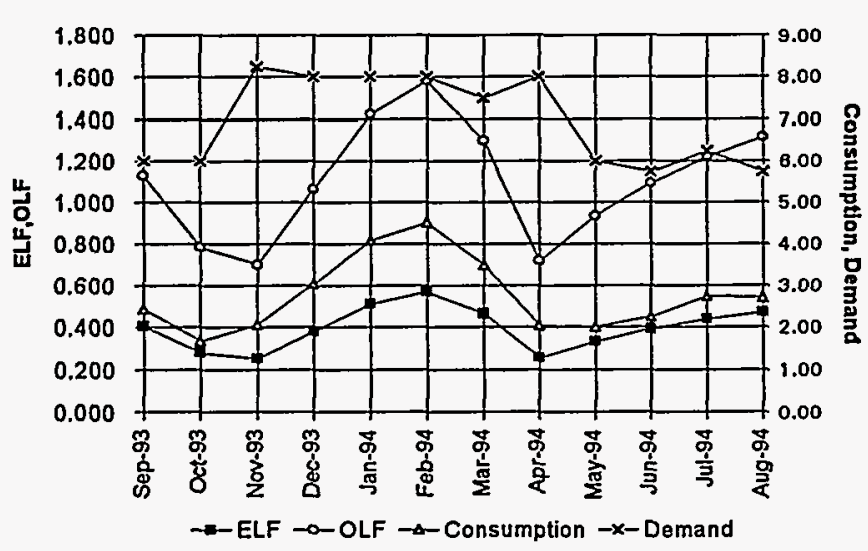

Figure 4.9 Monthly energy indices for Day Care Center \#1

Figure 4.9 illustrates the energy indices corresponding to the monthly utility data. Consumption and demand indices are higher than the screening limits during the heating season. Thus, the potential does exist for conservation during these months. While ELF's are not indicative of spikey profiles, their combination with larger OLF's are characteristic of excessive after-hour consumption. In fact, because OLF's are high in both heating and cooling seasons, and lower during neutral months, the after-hour consumption is probably by the HVAC system.

\subsubsection{Hourly Data}

The hourly profiles for a week in January 1993 and for a week in July 1993 are shown in Figures 4.10 (a) and (b). These figures confirm some of the conclusions made from the monthly utility data. Specifically, the jagged HVAC profile in January is representative of electricresistance heat. It is evident also that the heating and cooling system is operating, unnecessarily, during unoccupied hours and accounts for a large part of the total consumption. 

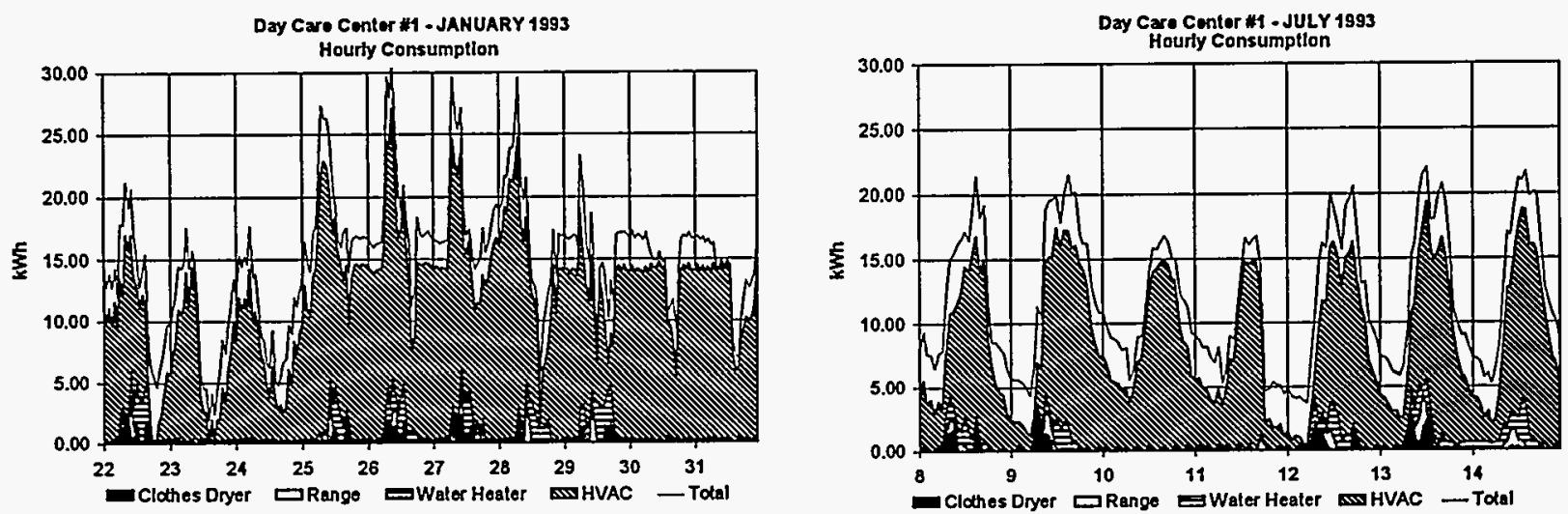

Figure 4.10 (a) Hourly end-use consumption, January 22 - 31, 1993 (b) Hoúrly end-use consumption, July 8 - 14, 1993, Day Care Center \#1

\subsection{ENERGY USE DATA FOR RESTAURANT \#2}

After the site-visit to Restaurant \#2, end-use hourly data was no longer available for this building because the customer had requested the equipment be removed. Since Restaurant \#2 is no longer participating in the end-use metering program, no further data or analysis will be presented in this report.

\subsection{ENERGY USE DATA FOR THE LIQUOR STORE}

\subsubsection{Monthly Data}

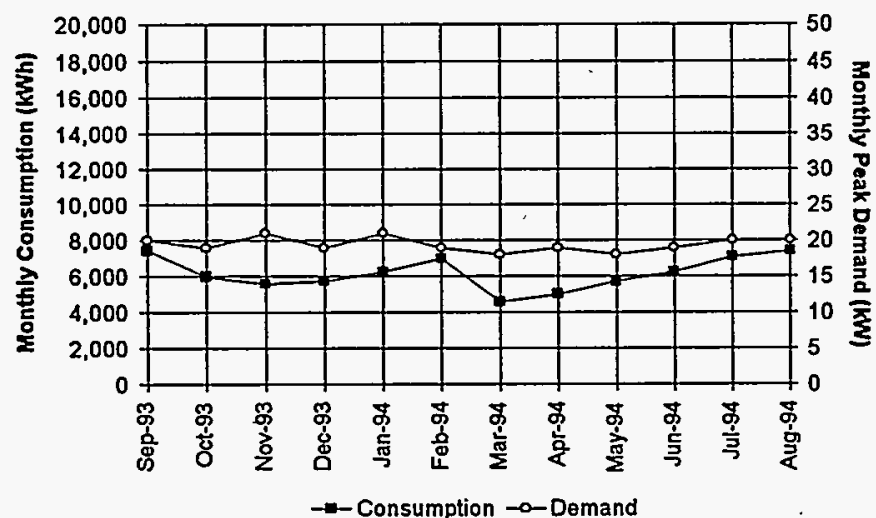

Figure 4.11 Monthly consumption and demand for the Liquor Store
Monthly consumption and demand taken from utility bills are shown in Figure 4.11. Consumption and demand profiles are nearly steady for the whole year examined. Annual consumption is $73,800 \mathrm{kWh}$, peak demand is $21 \mathrm{~kW}$, and utility costs are $\$ 5,700$, or $\$ 2.00 / \mathrm{ft}^{2}$. Slight 
dips in consumption do occur during swing periods in Spring and Fall. The absence of a large seasonal change in consumption and demand levels might indicate that a heat pump is used for heating and cooling.

Figure 4.12 provides a little more insight into the building's use of energy through the energy indices. Both demand and consumption indices are close to the screening limits of 3.0 $\mathrm{W} / \mathrm{ft}^{2}$ and $7.0 \mathrm{~W} / \mathrm{ft}^{2}$, respectively. These higher levels suggest that some potential exists for

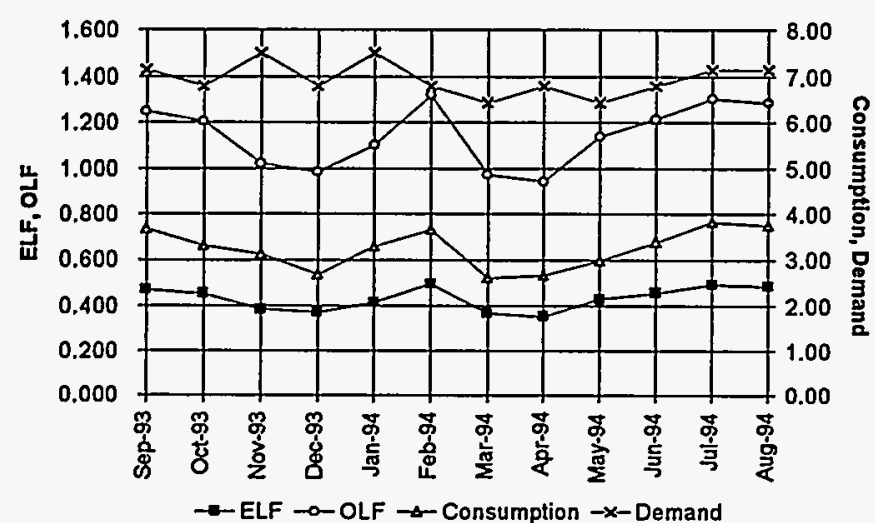

Figure 4.12 Monthly energy indices for the Liquor Store consumption and/or demand savings. Again the combination of mid-range ELF's and high OLF's are indicative of excessive afterhour consumption. The building representative claimed to have turned off HVAC equipment at night and ran the fans, alone, for ventilation.

\subsubsection{Hourly Data}

Hourly profiles for the Liquor Store are shown for a week in January 1993 and July 1993 in Figures 4.13 (a) and (b). These figures show that there is a great deal of after-hour consumption by both lighting and HVAC systems. The customer's claim that only ventilation fans are operated after-hours does not seem to be true, as is evident in the July data. The magnitude of the evening drop in total consumption is nearly equal to the reduction in lighting loads and not HVAC loads. Additionally, the spikey profiles in January are due to supplemental electric resistance heat used, in the morning hours, to restore setpoints after small night setbacks. An automated control system could eliminate these spikes by ramping up the morning setpoints, thus reducing the need for electric-resistance supplemental heat. 

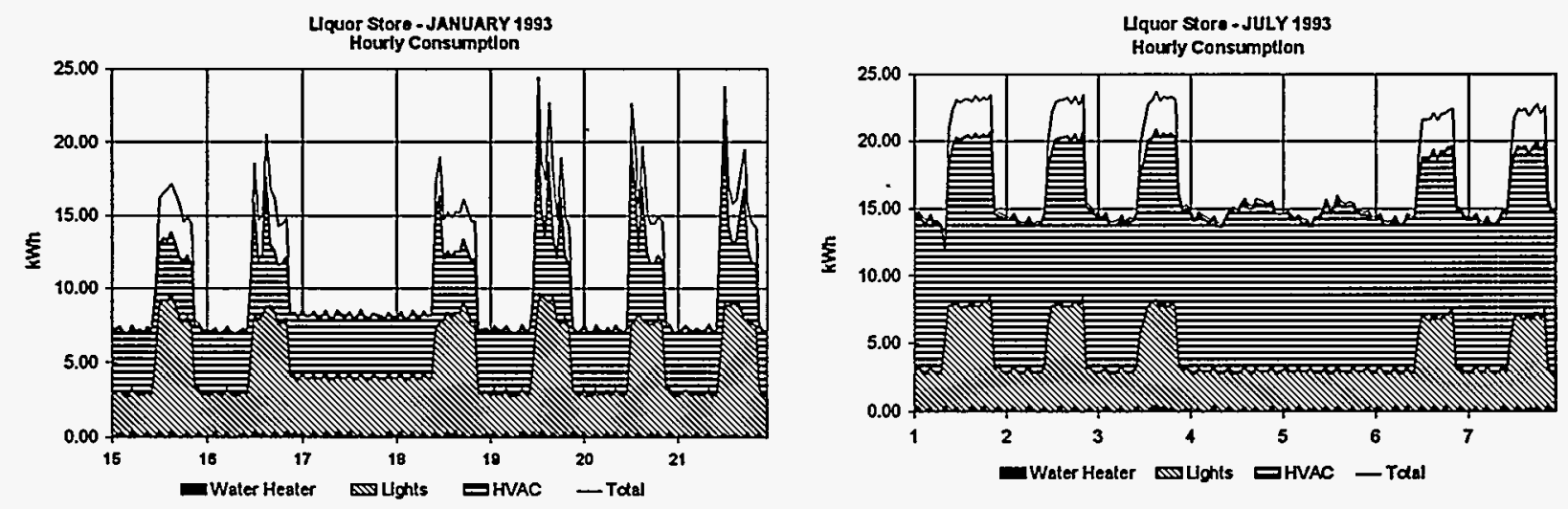

Figure 4.13 (a) Hourly end-use consumption, January $15-21,1993$ (b) Hourly end-use consumption, July $1-7,1993$, Liquor Store

\subsection{ENERGY USE DATA FOR THE BANK}

\subsubsection{Monthly Data}

Both demand and consumption profiles are seasonal for the Bank, (Figure 4.14). Annual consumption and demand levels, and utility costs from September 1993 through August 1994 are $79,700 \mathrm{kWh}, 35 \mathrm{~kW}$ and $\$ 5,400\left(\$ 1.45 / \mathrm{ft}^{2}\right)$, respectively. The large swings in these profiles indicate that the building is highly weather dependent.

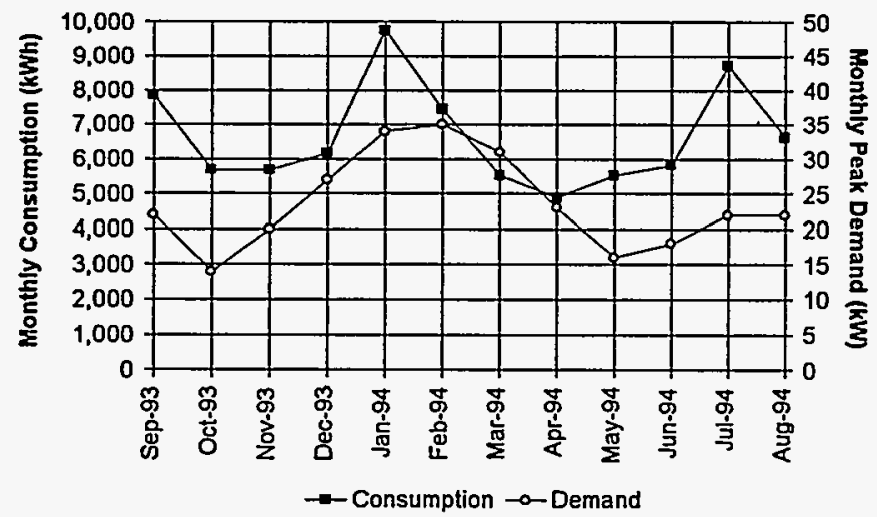

Figure 4.14 Monthly consumption and demand for Bank
The Bank is the only building sampled which uses the Duke Power Schedule G rate structure. Recall that Schedule G does not include seasonal variances in utility costs. Alternatively, Schedule GA experiences a reduction in energy costs during the heating months of December through March. Since the Bank 
seems to have seasonal variances in consumption and in demand, it would be advantageous for them to contract under Schedule $G A$, in order to obtain lower winter utility costs.

Monthly energy indices for September 1993 through August 1994 are shown in Figure 4.15 , for the Bank. Once again these indices provide more insight into the use of energy in the building. Specifically, consumption levels are not unlike those of similar buildings. Interestingly though, OLF's are greater than 1.0 for the whole period examined. Demand levels, conversely,

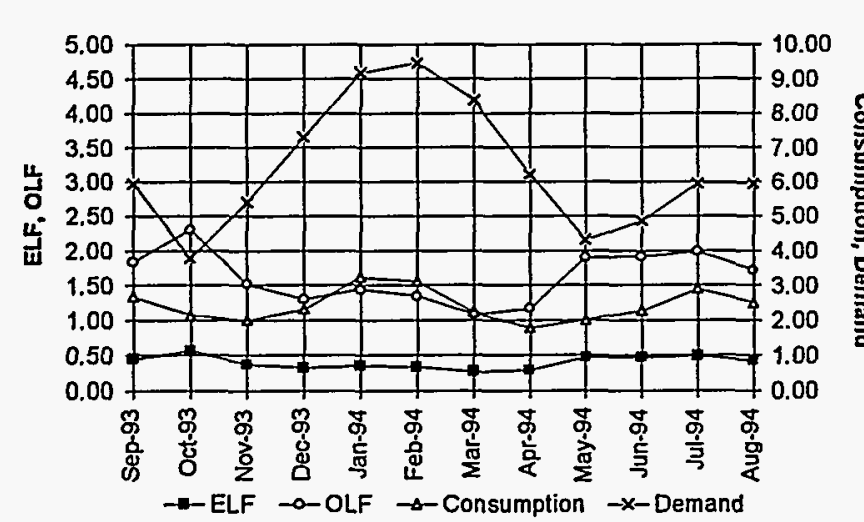

Figure 4.15 Monthly energy indices for Bank are especially high during the heating season, yet reasonable during the cooling season. The ELF's, however do not reflect a spikey consumption profile, as both consumption and demand are increased during the heating months.

\subsubsection{Hourly Data}

Once again hourly data is found to be helpful in determining energy conservation opportunities. Figures 4.16 (a) and (b) show hourly profiles for a week in January 1993 and a week in July 1993, respectively. Recall from the audit information gathered that the bank is heated and cooled by a large heat pump and by a small air-conditioner with electric-resistance heat. The profile in January indicates some supplemental electric-resistance heat during startup. Also, there is some evidence here of manual setbacks, however it seems to be rather inconsistent. A programmable control system for the HVAC system would solve these problems. 

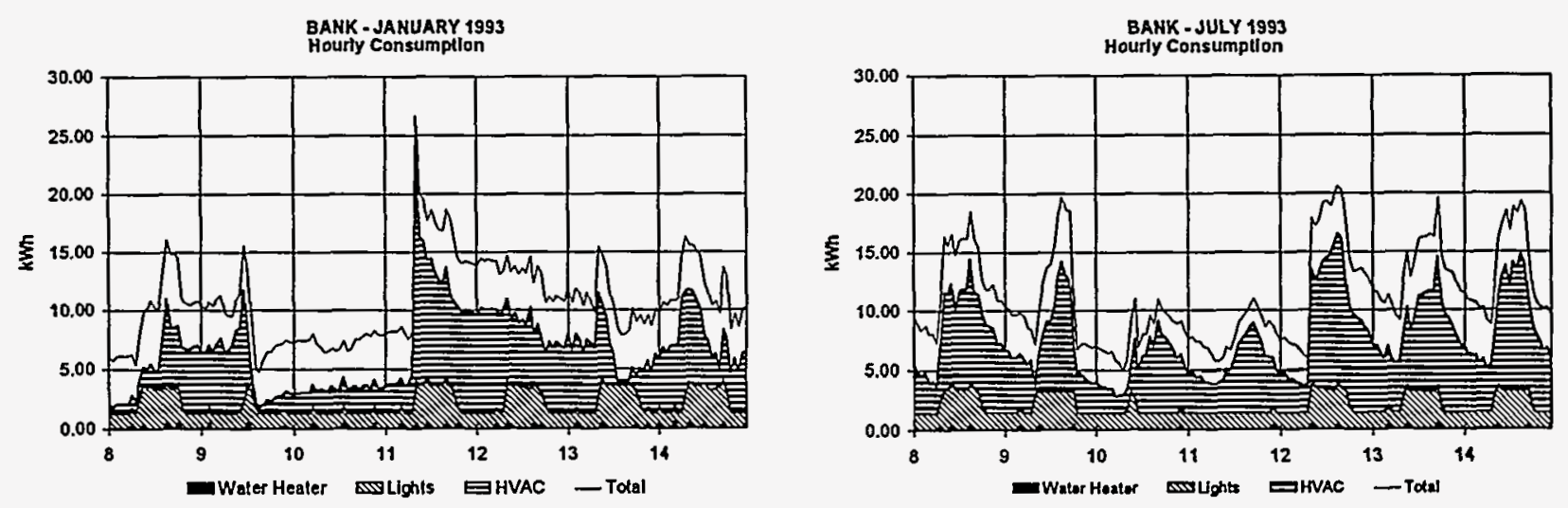

Figure 4.16 (a) Hourly end-use consumption, January $8-14,1993$ (b) Hourly end-use consumption, July 8 - 14, 1993, Bank

\subsection{SUMMARY OF ENERGY USE DATA}

A great deal of energy use data was available for the buildings examined. These data include monthly utility bills and hourly end-use profiles from June 1992 through August 1994. By using energy indices calculated with monthly consumption and demand values, preliminary hypotheses can be drawn regarding energy conservation opportunities. Viewing monthly consumption and demand profiles also helps to determine if weather is a variable in building behavior.

The hourly end-use data were also extremely helpful in several ways. First, after-hour consumption, or demand spikes, as predicted by ELF's and OLF's, were verified with the hourly data. Second, hourly data were used in estimating end-use loads in the conservation analysis. Finally, the data were found to be extremely helpful in aiding the audit team members in locating and identifying significant building loads. 


\section{ANALYSIS OF POTENTIAL ENERGY MEASURES}

Using the information gathered from site inspections and from monthly and hourly data, potential energy measures for each building were determined. A simplified model of each building was then developed using the DOE-2.1D simulation software. The models were calibrated using weather data representing a typical meteorological year', (TMY), and actual building data spanning from July 1993 through June 1994. As a result of using the TMY weather data, actual consumption and demand peaks that occurred during months with unusual weather conditions will not be duplicated in the simulation models. Additionally, the results of the simulation analyses that follow are only approximate since they are developed from the simplified model and are only meant to estimate potential savings. More detailed modeling should be considered in the future.

\subsection{POTENTIAL ENERGY MEASURES FOR RESTAURANT \#1}

Opportunities for saving energy in Restaurant \#1 restaurant include lighting and control retrofits. While other possibilities may exist with the food preparation equipment, such measures were not included here because they are so specialized. Figures 5.1 and 5.2 show the monthly consumption and demand profiles for the actual building, the base (pre-retrofit) model, and for

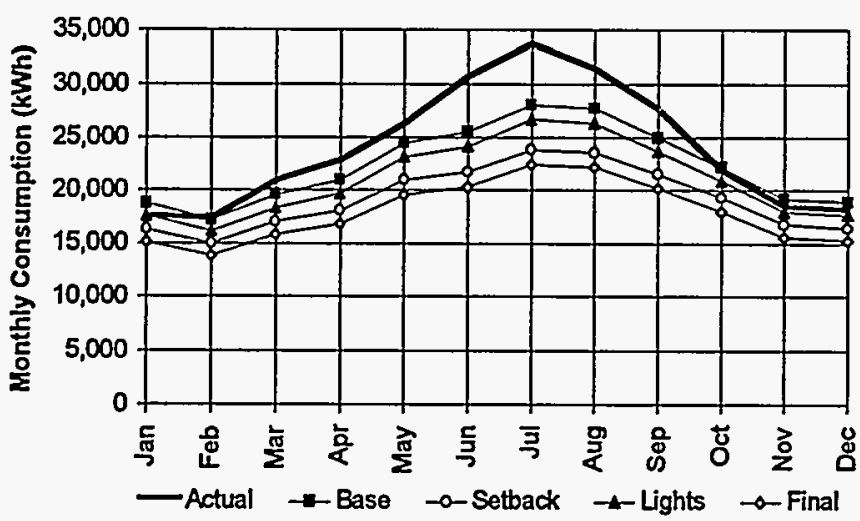

Figure 5.1 Monthly energy consumption comparison of actual and simulated models, Restaurant \#1 individual and combined retrofit models.

Inefficient fluorescent kitchen and incandescent dining area lighting systems present plenty of opportunity for conservation. By replacing the 40 W, 2-lamp magnetic ballast 
fixtures with $32 \mathrm{~W}$, 4-lamp electronic ballast fixtures and reducing overlit conditions, lighting capacity is reduced from $1.8 \mathrm{~W} / \mathrm{ft}^{2}$ to less than $1.0 \mathrm{~W} / \mathrm{ft}^{2}$ in the kitchen area. Additionally, $75 \mathrm{~W}$ incandescent spots could be replaced with efficient $60 \mathrm{~W}$ spots at a loss of only 130 lumens per lamp. This would reduce the dining area lighting capacity from $1.48 \mathrm{~W} / \mathrm{ft}^{2}$ to $1.18 \mathrm{~W} / \mathrm{ft}^{2}$. This lighting retrofit alone would provide $15,300 \mathrm{kWh}$ and $3.0 \mathrm{~kW}$ in consumption and demand savings, respectively. Also, a coat of light-colored, reflective paint on the walls would alleviate lighting problems.

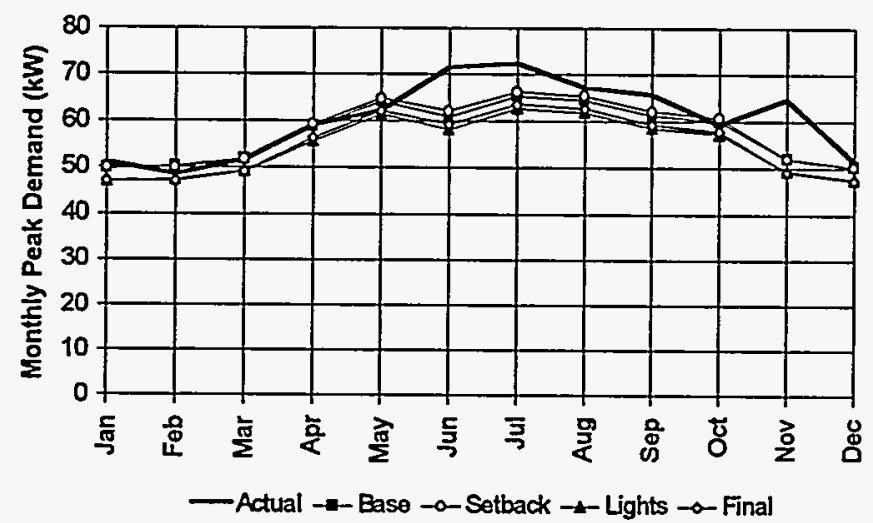

Figure 5.2 Monthly demand comparison of actual and simulated models, Restaurant \#1
The monthly and hourly data showed that a great deal of consumption by air-conditioning equipment occurs after-hours. The site-visit found that thermostats were adjusted at random by staff and patrons. The second retrofit considered for this restaurant is a programmable thermostat. By reducing the heating set points by $8-10^{\circ} \mathrm{F}$ and increasing the cooling set points by $10-12^{\circ} \mathrm{F}$, after-hour HVAC consumption can be greatly reduced. Specifically, energy savings predicted by the model could be as high as $37,000 \mathrm{kWh} / \mathrm{yr}$. Unfortunately, setbacks have the potential to boost peak demand levels - as is seen with the model. The programmable thermostat should be configured to slowly ramp set points to their daytime values, in order to eliminate demand spikes.

Finally, the combination of the lighting and control retrofits should provide the most energy savings. Annual energy savings for the combined model are over $52,000 \mathrm{kWh}$ and peak demand savings are predicted to be above $3.0 \mathrm{~kW}$. Little reaction occurs between these two retrofits as lights are generally turned off at night when the setbacks are most beneficial. Thus, the resulting savings are nearly the combination of savings from individual models. 
(A cost savings analysis for Restaurant \#1 is not available at this time due to the absence of utility rate information)

\subsection{POTENTIAL ENERGY MEASURES FOR CLOTHING STORE}

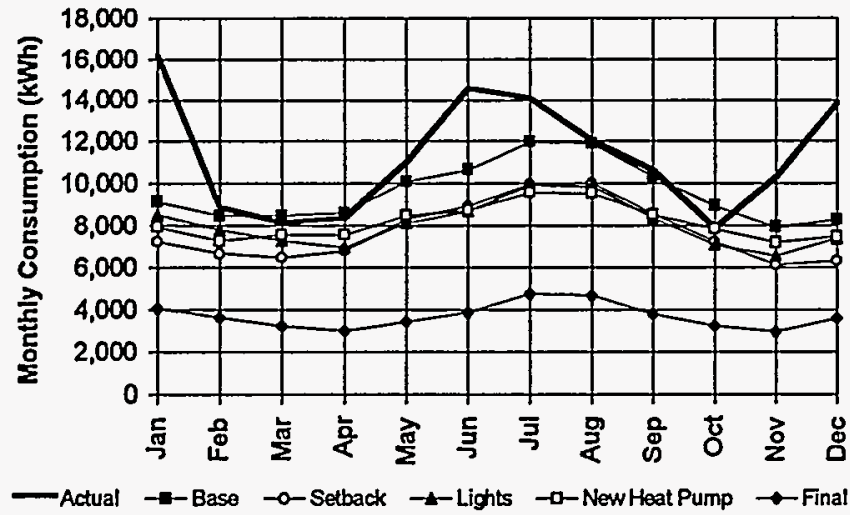

Figure 5.3 Monthly energy consumption comparison of actual and simulated models, Clothing Store
The potential energy measures considered for the Clothing Store consist of lighting, controls, and HVAC system retrofits. The management at the Clothing Store has indicated that a comprehensive lighting retrofit was to be implemented in July 1994 ,

after the ORNL/Duke Power site-visit. The management also suggested the need for new airconditioning, as one of the older units does not provide adequate cooling capacity. Control problems were made evident by monthly and hourly data which revealed a considerable amount of after-hour HVAC consumption. Figures 5.3 and 5.4 show the results of the simulation analysis.

Although the manager indicated that the HVAC equipment was turned-off at night, hourly data indicated otherwise. Installation of a programmable thermostat would likely ensure that these units are shut-off during unoccupied hours. The model implemented cooling set points of $80^{\circ} \mathrm{F}$ and heating set points of $60^{\circ} \mathrm{F}$, during after-hours. Annual energy savings associated with this retrofit, alone, are over $22,000 \mathrm{kWh}$. Although the peak demand is increased in the setback model by $2.7 \mathrm{~kW}$, a well-calibrated control system should eliminate these increases altogether. 


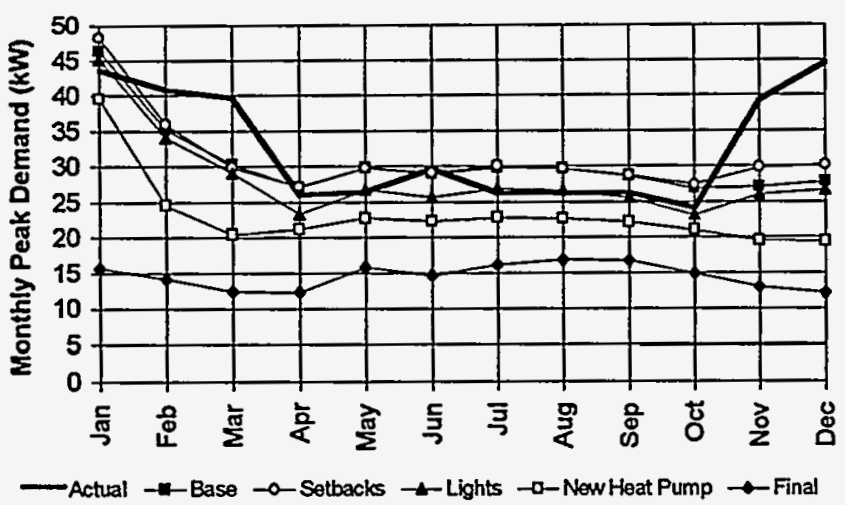

Figure 5.4 Monthly demand comparison of actual and simulated models, Clothing Store
The next conservation opportunity considered was a lighting retrofit. By replacing the 34 W, 2-lamp magnetic ballast fixtures with $32 \mathrm{~W}$, 4-lamp electronic ballast fixtures, and by replacing $75 \mathrm{~W}$ and $150 \mathrm{~W}$ spots with $60 \mathrm{~W}$ and $120 \mathrm{~W}$ spots, the total lighting capacity may

be reduced from $3.0 \mathrm{~W} / \mathrm{ft}^{2}$ to $2.1 \mathrm{~W} / \mathrm{ft}^{2}$. Annual potential energy savings from a lighting retrofit of this kind are $18,000 \mathrm{kWh}$, with a peak demand savings of $3.84 \mathrm{~kW}$. Savings are smaller during the cold months as the electric-resistance heating system works to accommodate the heating effect previously supplied by the lights. Further consumption savings could occur if the spot lights in the front windows are put on light sensors so that they only operate when actually needed.

Finally, the installation of a new heat pump is yet another energy conservation opportunity for this building. The existing units have electric-resistance heat and are also rather inefficient on the cooling side. By replacing the old units with new energy-efficient heat pumps, approximately $17,000 \mathrm{kWh}$ of energy can be saved annually and peak demand may be reduced by more than $10 \mathrm{~kW}$.

The combination of all three of these retrofits leads to excellent energy and demand savings. The potential energy savings of the overall model are $70,600 \mathrm{kWh}$, with a peak demand savings of $30 \mathrm{~kW}$. Incredibly, consumption with the full retrofit scenario is projected to be only $34 \%$ of the $1993 / 1994$ base consumption (Table 2.2). Similarly, peak demand should be reduced by $35 \%$. 
Figure 5.5 presents the monthly utility costs associated with each scenario, as based on the July $1,1993 \mathrm{GA}$ rate schedule. Individually, setback savings are $\$ 1,070$, lighting savings

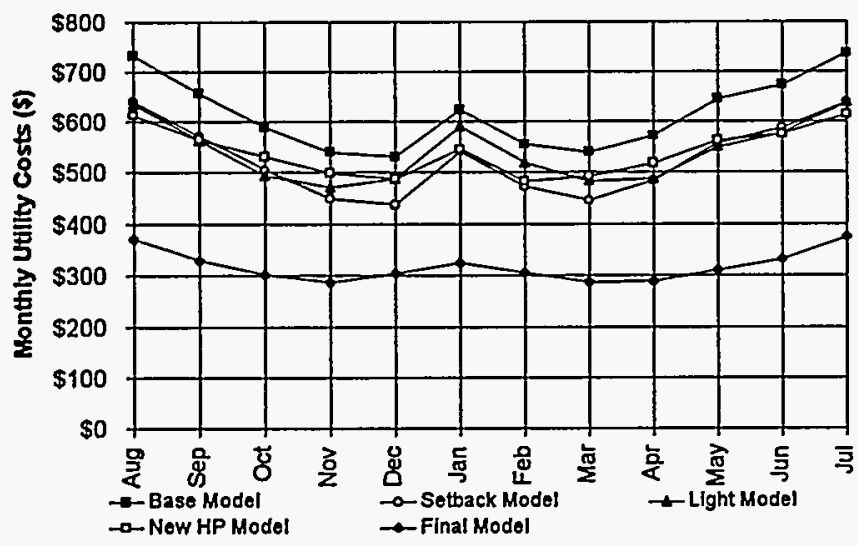

Figure 5.5 Monthly utility cost comparisons of base and simulated models, Clothing Store are $\$ 900$, and heat pump savings are $\$ 900$. If all retrofits are installed, potential annual savings could top $\$ 3,600$, which represents $43 \%$ of the total $1993 / 1994$ utility costs. Additional cost savings are expected if lamps and ballasts are made compatible.

\subsection{POTENTIAL ENERGY MEASURES FOR DAY CARE CENTER \#1}

Since efficient lighting is already installed in the Day Care Center building, the remaining opportunities for energy conservation lie with control and heat pump retrofits. The results of the energy simulation model are shown in Figures 5.6 and 5.7, for consumption and demand respectively.

From the monthly data it was evident that the Day Care Center consumes a great deal of energy during unoccupied hours. The data also showed that excess consumption was minimized

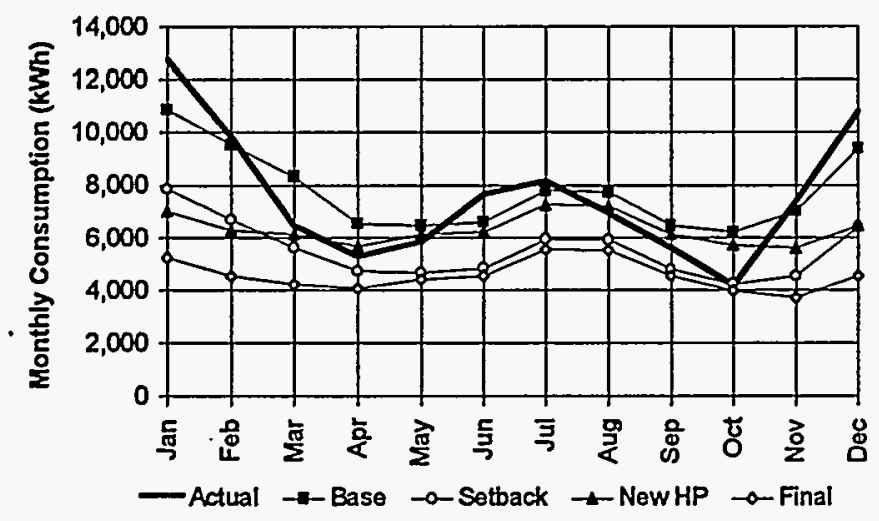

Figure 5.6 Monthly energy consumption comparison of actual and simulated models, Day Care Center \#1 during the neutral months. Thus, it was determined that most of the after-hour consumption is a result of an unregulated HVAC system. The hourly data also verified this problem. By implementing afterhour set points of $60^{\circ} \mathrm{F}$ for heating, and $80^{\circ} \mathrm{F}$ for cooling, a great deal of 
energy may be conserved. According to the model, setbacks alone would annually save 26,500 $\mathrm{kWh}$. The model does predict an increase in demand, associated with the setbacks. A well calibrated control system should alleviate this problem by slowly ramping up temperatures in the hours just before the occupants arrive.

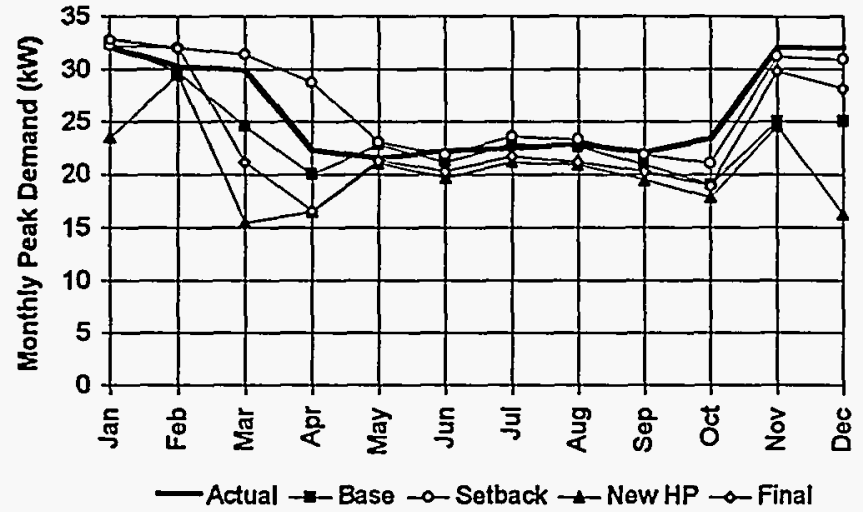

Figure 5.7 Monthly demand comparison of actual and simulated models, Day Care Center \#1
Recall that this building is heated with electric resistance heat, which is reflected by increased consumption and demand levels during the heating months. The savings potential is attractive if the present HVAC system is replaced with an efficient electric heat pump.

Specifically, annual energy savings are predicted to be $17,000 \mathrm{kWh}$, with a peak demand reduction of $9 \mathrm{~kW}$.

The best savings potential occurs when both retrofits are combined together. It is also best to use a programmable thermostat with a heat pump in order to achieve the full potential demand savings by reducing the need for supplement electric-resistance heat. The estimated annual energy savings are over $38,000 \mathrm{kWh}$, with corresponding peak demand reduction of 3.4 kW. This reduces the building's consumption to $56 \%$ of the $1993 / 1994$ value, (Table 2.2).

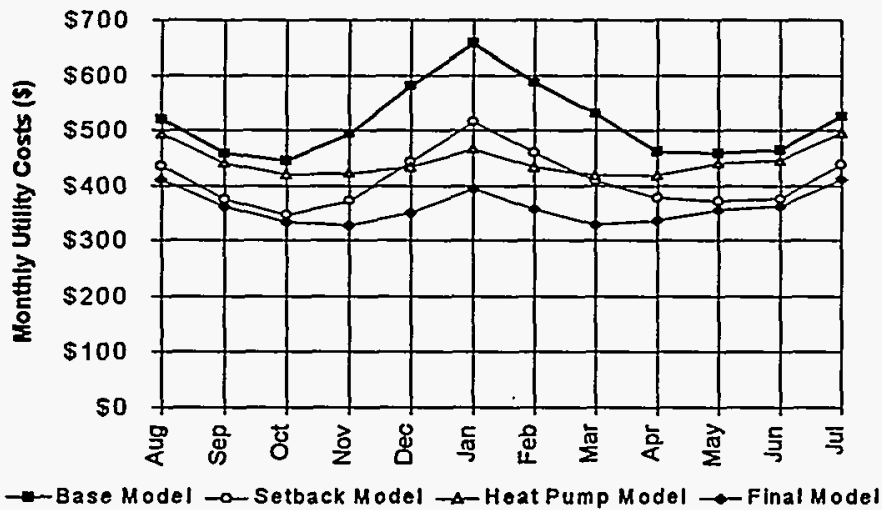

Figure 5.8 Monthly utility cost comparisons of actual and simulated models, Day Care Center \#1
Figure 5.8 gives the monthly utility costs corresponding to each retrofit scenario, based on the $G A$ schedule, effective July 1, 1993. The installation of HVAC controls, alone, would save over $\$ 1,200$ per year. A heat pump retrofit, alone, would save $\$ 850$ per year in utility 
costs. The combination of both retrofits has the greatest annual savings, at approximately $\$ 1,850$. This represents an annual utility bill savings of $30 \%$.

\subsection{POTENTIAL ENERGY MEASURES FOR LIQUOR STORE}

The suggested energy conservation measures for the Liquor Store include HVAC control and lighting retrofits. The site-visit found that the HVAC system for this building was running during unoccupied periods. In fact, the fans were always left on, as opposed to cycling along with the system. Additionally, the retail sales area was found to be overlit, with an inefficient lighting system. Figures 5.9 and 5.10 present the results for consumption and demand obtained with the simulation models.

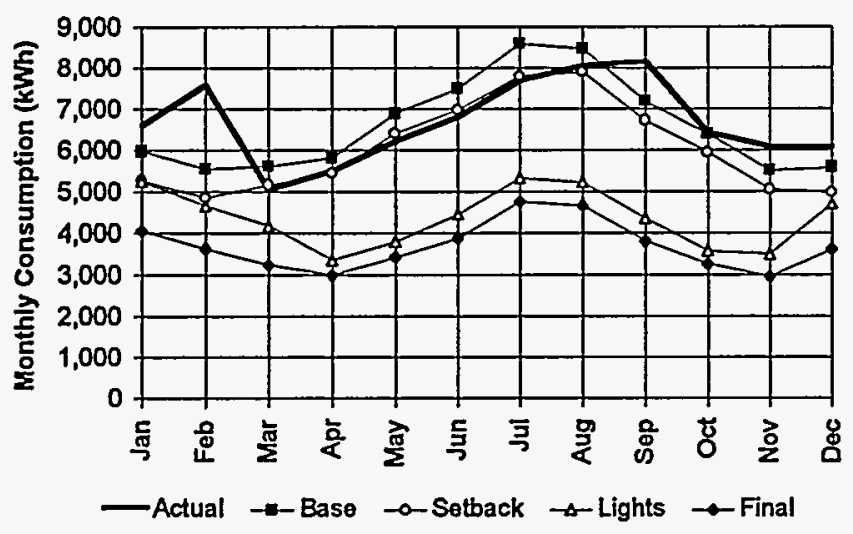

Figure 5.9 Monthly energy consumption comparison of actual and simulated models, Liquor Store

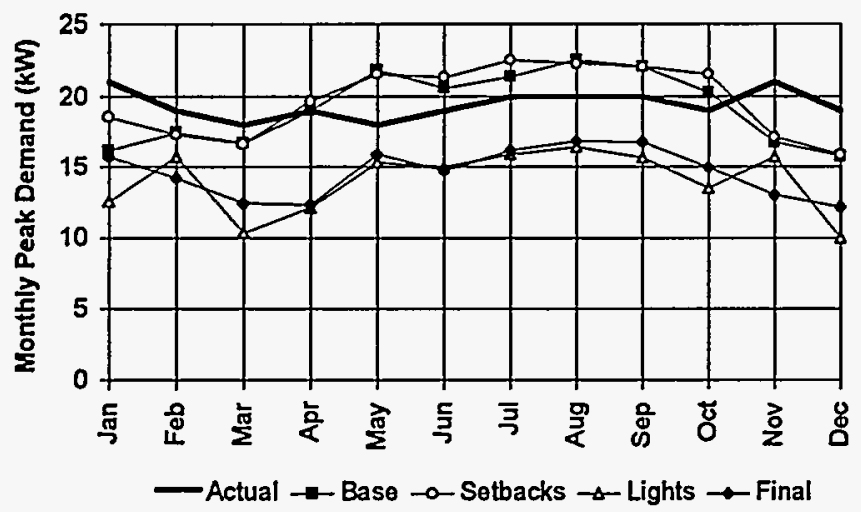

Figure 5.10 Monthly demand comparison of actual and simulated models, Liquor Store
Despite the claim of the building representative, monthly and hourly data showed that the HVAC system was running excessively overnight. A programmable control system will alleviate this problem and ensure that temperatures are set back properly and regularly. The simulation model had unoccupied heating and cooling set points of $60^{\circ}$ $F$ and $80^{\circ} \mathrm{F}$, respectively. This resulted in an annual energy savings of $6,500 \mathrm{kWh}$ with a negligible reduction in demand.

The lighting levels in this store were extremely high, at 120 to 
130 foot-candles. The present system, which uses $40 \mathrm{~W}$ and $75 \mathrm{~W}$ T-12 lamps, (apparently with 2-lamp magnetic ballasts), has a capacity of $3.25 \mathrm{~W} / \mathrm{ft}^{2}$. By reducing the lighting level to 80 footcandles and replacing fixtures with 32 W T-8 lamps with 4-lamp electronic ballasts, the lighting capacity is reduced to $1.66 \mathrm{~W} / \mathrm{ft}^{2}$. The annual energy savings would be nearly $26,600 \mathrm{kWh}$, with a reduction in peak demand of over $6 \mathrm{~kW}$. Additional energy savings would occur if motion sensors are used to control the lights in the storage and office areas.

The combination of both retrofits provides the largest amount of savings. The energy savings for the combined scenario are $34,700 \mathrm{kWh}$, which is a $43 \%$ reduction in annual consumption. The peak demand savings, for the two retrofits together, are estimated to be 6.5 $\mathrm{kW}$.

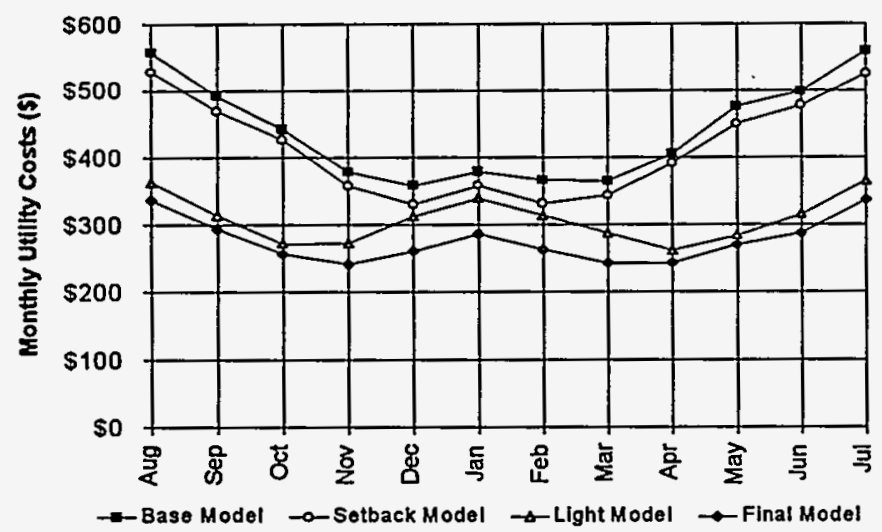

Figure 5.11 Monthly utility cost comparison of actual and simulated models, Liquor Store
Figure 5.11 shows the utility costs for each retrofit scenario. Annual cost savings from setbacks alone are $\$ 290$, while utility cost savings from the lighting retrofit would be over $\$ 1,500$. The combined retrofit model has an estimated savings of $\$ 1,950$, which reflects a $37 \%$ reduction in utility costs.

\subsection{POTENTIAL ENERGY MEASURES FOR BANK}

The manager at the Bank expressed great interest in a conservation program for his branch office. The items most attractive for retrofit were lighting and HVAC setback. While the manager claimed to be personally dedicated to reducing his energy costs, the monthly and 
hourly data did not reflect his attempts. Figures 5.12 and 5.13 present the results found with the energy simulation analysis of the retrofit scenarios.

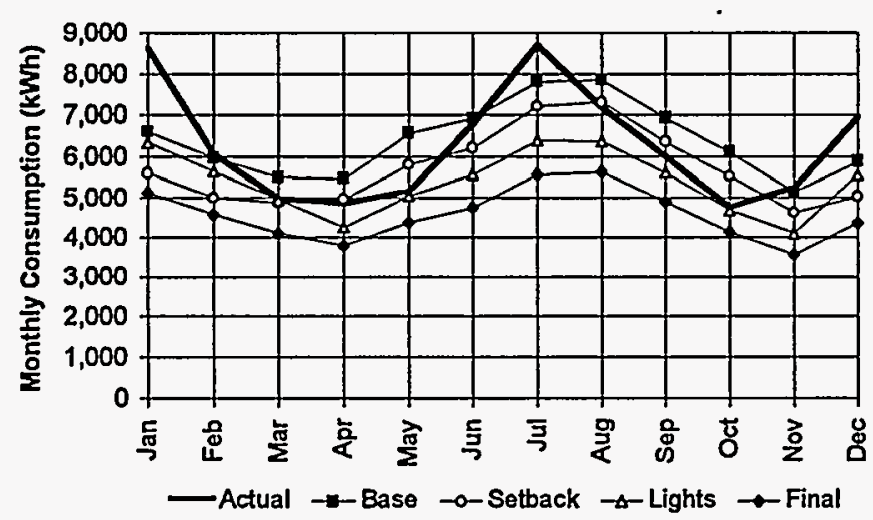

Figure 5.12 Monthly energy consumption comparison of actual and simulated models, Bank
Lighting problems were most evident during the site-visit. The teller area had inefficient fixtures using $40 \mathrm{~W}$ lamps with 2lamp magnetic ballasts. Additionally, $60 \mathrm{~W}$ spot lights were used to light a hallway and some office areas. A new lighting system incorporating 32 W T-8 lamps with 4-lamp electronic ballasts will reduce lighting capacity from $3.25 \mathrm{~W} / \mathrm{ft}^{2}$ to $1.66 \mathrm{~W} / \mathrm{ft}^{2}$. The predicted energy savings should be nearly $12,000 \mathrm{kWh}$ per year, with peak demand reduction of $4.8 \mathrm{~kW}$.

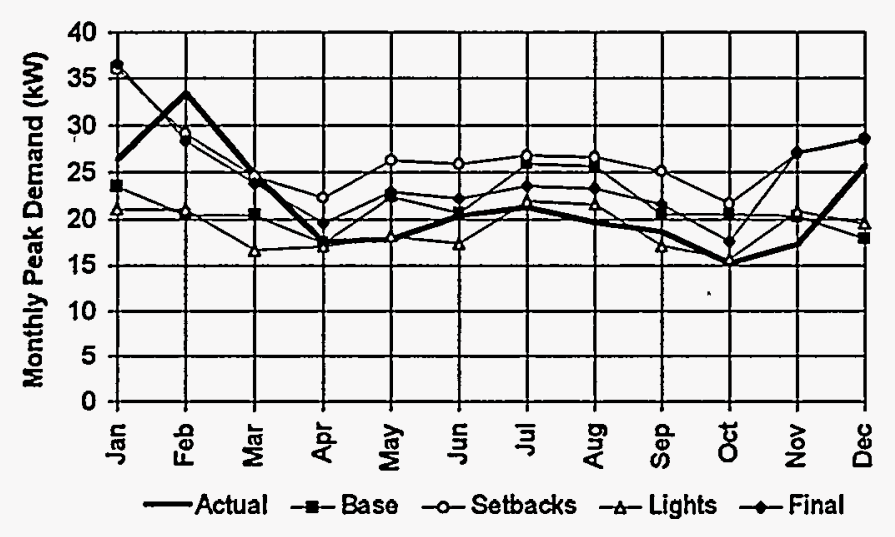

Figure 5.13 Monthly demand comparison of actual and simulated models, Bank
In order to eliminate the unnecessary after-hour consumption by the HVAC system, a programmable thermostat is recommended. Again, with an after-hour cooling set point of $80^{\circ} \mathrm{F}$ and a heating set point of $60^{\circ} \mathrm{F}$, a great deal of energy may be

conserved. Setback savings for the model, annually, are $8,200 \mathrm{kWh}$. The model again predicts negative demand savings, however more detailed programming of the thermostat should help avoid this problem. 
Energy savings are enhanced when these two retrofits are combined. Specifically, consumption savings are over $21,800 \mathrm{kWh}$, with a peak reduction in demand of $2.8 \mathrm{~kW}$. This represents a reduction in annual consumption of $28 \%$.

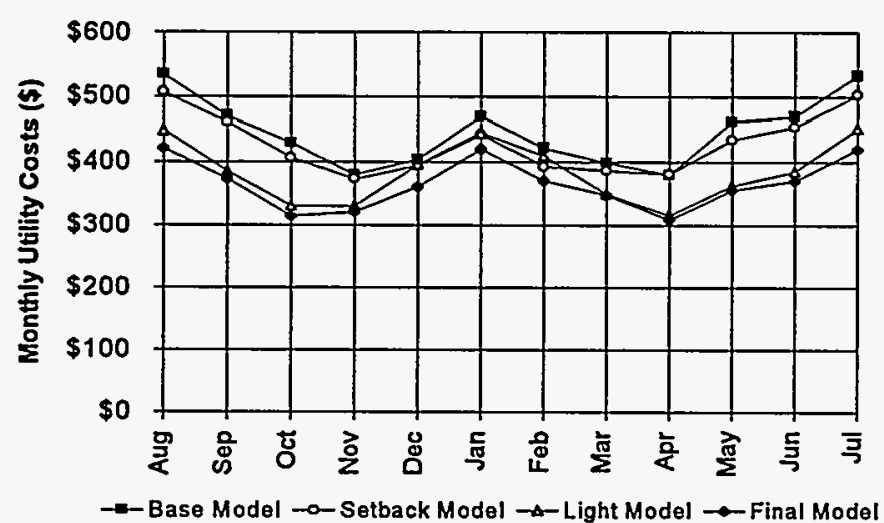

Figure 5.14 Monthly utility cost comparison of actual and simulated models, Bank
Figure 5.14 illustrates the utility costs associated with the retrofits considered, based on Schedule G, effective July 1, 1993. The cost savings of the control retrofit is $\$ 210$, per year. Savings from lighting retrofits are higher, at $\$ 740$ per year. The combination of setback control and lighting retrofits should save over $\$ 950$ per year, which is an $18 \%$ reduction in energy costs. Further cost savings may be possible if the Bank were to switch to the GA rate schedule, which utilizes lower energy costs during the months of December through March.

\subsection{SUMMARY OF POTENTIAL MEASURES}

After examining data and performing site-visits, retrofits were selected that were expected to have a high potential for saving energy. Recommended retrofits included lighting, HVAC control and new HVAC equipment. Simulations of annual energy consumption for each building were performed for each retrofit scenario. Table 5.1 lists each candidate and the resulting energy and cost savings estimated for recommended retrofits. 


\begin{tabular}{|c|c|c|c|c|}
\hline Name & Lighting & Controls & HVAC & Total \\
\hline Restaurant \#1 & $15,300 \mathrm{kWh}, 3 \mathrm{~kW}$ & $37,000 \mathrm{kWh},-1.2 \mathrm{~kW}$ & & $52,000 \mathrm{kWh}, 3 \mathrm{~kW}$ \\
\hline Clolhing Store & $\begin{array}{c}18,000 \mathrm{kWh}, 3.8 \mathrm{~kW} \\
\$ 900\end{array}$ & $\begin{array}{c}22,000 \mathrm{kWh},-2.7 \mathrm{~kW} \\
\$ 1,070\end{array}$ & $\begin{array}{c}17,000 \mathrm{kWh}, 10 \mathrm{~kW} \\
\$ 900\end{array}$ & $\begin{array}{c}70,600 \mathrm{kWh}, 30 \mathrm{~kW}, \\
\$ 3,600\end{array}$ \\
\hline Day Care Center \#1 & & $\begin{array}{c}26,500 \mathrm{kWh},-8 \mathrm{~kW} \\
\$ 1,200\end{array}$ & $\begin{array}{c}17,000 \mathrm{kWh}, 9 \mathrm{~kW} \\
\$ 850\end{array}$ & $\begin{array}{c}38,000 \mathrm{kWh}, 3.4 \mathrm{~kW}, \\
\$ 1,850\end{array}$ \\
\hline Liquor Store & $26,600 \mathrm{kWh}, 6 \mathrm{~kW}$ & $\begin{array}{c}6,500 \mathrm{kWh},-2 \mathrm{~kW} \\
\$ 1,500\end{array}$ & & $\begin{array}{c}34,700 \mathrm{kWh}, 6.6 \mathrm{~kW}, \\
\$ 1,950\end{array}$ \\
\hline Bank & $\begin{array}{c}12,000 \mathrm{kWh}, 4.8 \mathrm{~kW} \\
\$ 740\end{array}$ & $\begin{array}{c}8,200 \mathrm{kWh},-12 \mathrm{~kW} \\
\$ 210\end{array}$ & $\begin{array}{c}21,800 \mathrm{kWh}, 2.8 \mathrm{~kW}, \\
\$ 950\end{array}$ \\
\hline
\end{tabular}

Table 5.1 Summary of potential energy, demand and cost savings, per scenario

It is recommended that no conservation measures be installed blindly and that efforts are made to ensure proper design and application. Experience with controls measures in small buildings indicates that most are not kept functioning properly, even over a short period of time. Thus, some means of assuring reasonable retention of control capabilities is necessary before field testing of energy savings is conducted. Effective maintenance of HVAC systems is also a problem, but is often less damaging to energy savings than the lack of control capability. Additionally, lighting retrofits installed in a building heated by electric-resistance heat will have smaller savings during winter months, as the system must accommodate the loss of heat which was previously supplied by the lights. Success is only assured when retrofits are properly applied and implemented.

\section{CONCLUSIONS AND RECOMMENDATIONS}

The study of small commercial buildings in North Carolina has shown many important results. First, for small commercial buildings that had higher values of the screening indices, there is significant energy savings potential. The energy savings identified amount to about $25 \%$ of the total energy consumption for these buildings. Demand savings were less consistent, ranging from $4 \%$ to $67 \%$, but typically were more in the range of a $10 \%$ reduction. The audit 
screening methods used seemed to have real potential for simplifying identification of candidate buildings in the future. Study of additional buildings is necessary to determine if this level of savings potential exists for buildings with more average levels of the screening indices.

The energy savings were largely in two major areas: lighting and HVAC controls. The lighting measures are typical of what can be expected for commercial buildings, and the site audits showed strong potential for lighting retrofits in this sector. The HVAC controls measures are much more difficult, in that occupants appear unaware of exactly what they are doing with the HVAC controls. It would be unreasonable to expect them to know what the energy use and demand impacts of their actions are, however, they do not even appear to understand when the HVAC system will be on or off in some cases. Overall, some significant issues relative to user control of HVAC systems surfaced.

Replacement of heating and cooling systems appears marginally justified in some buildings, and occasional poor heating and cooling performance of systems may indicate an important opportunity to address customer problems while achieving some efficiency improvements. Methods for locating poorly performing cooling systems may be particularly important for small commercial buildings in the southern part of the United States. Further work on developing such methods may be justified.

The audit screening indices, based on monthly energy use and demand data and information about building gross floor area and operating hours, provided important information that was corroborated by hourly end-use energy data. These indices appear to offer potential for screening of buildings to identify good candidates for different types of retrofit measures.

The cost savings for the measures in these buildings indicate the difficulty of working with such small buildings. Savings of $\$ 1,000$ to $\$ 4,000$ per year mandate that the amount of engineering time spent identifying and designing measures be kept at a minimum. Automation of procedures to the largest extent possible appears necessary to allow services to be offered at a reasonable premium for the value obtained. 
Overall, the significant savings indicates that study of actual installations of measures, to verify performance, would be worthwhile. However, it is recommended that the consideration of . field testing should not proceed until methods can be developed for retention of HVAC control capabilities and, possibly also, HVAC system capabilities. 


\section{REFERENCES}

Haberl, J.S. and P.S. Komor 1989. "Investigating an Analytical Basis for Improving Commercial Building Energy Audits: Early Results from a New Jersey Mall," Proceedings from Thermal Performance of the Exterior Envelopes of Buildings IV, pp. 587-612.

Duke Power 1993a. Schedule GA (NC) General Service, All-Electric, July 1, 1993, NCUC Docket No. E-7. Sub 517.

Duke Power 1993b. Schedule G (NC) General Service, All-Electric, July 1, 1993, NCUC Docket No. E-7. Sub 517.

Duke Power 1993c. Schedule OPT (NC) General Service, All-Electric, July 1, 1993, NCUC Docket No. E-7. Sub 517.

EIA 1992. Commercial Buildings Energy Consumption and Expenditures 1989, U.S. Energy Information Administration, DOE/EIA-0318(89).

EIA 1994. Commercial Buildings Characteristics 1992, U.S. Energy Information Administration, DOE/EIA-0246(92).

MacDonald, J.M., T.R. Sharp and M.B. Gettings 1989. A Protocol for Monitoring Energy Efficiency Improvements in Commercial and Related Buildings, Oak Ridge National Laboratory, ORNL/CON-291.

MacDonald, J. M. 1986. "A Research Plan for Commercial Sector Retrofits," Proceedings from the ACEEE 1986 Summer Study on Energy Efficiency in Buildings, Vol. 3.

OBT 1994. Core Databook, U.S. Dept. of Energy, Office of Building Technologies, Washington: U.S. DOE., EE-40, 1000 Independence Ave., S.W., 20585. 


\section{INTERNAL DISTRIBUTION}

\begin{tabular}{|c|c|c|c|}
\hline 1 & M. M. Abraham & 15 & R. L. Shelton \\
\hline 2 & V. D. Baxter & 16 & M. P. Ternes \\
\hline 3 & M. A. Brown & 17 & J. J. Tomlinson \\
\hline 4 & G. E. Courville & 18 & R.L. Wendt \\
\hline 5 & L. S. Edwards & $19-78$ & Energy Conservation Dist., \\
\hline 6 & M. B. Gettings & & Building 3147, MS-6070 \\
\hline 7 & S. G. Hildebrand & 79 & Central Research Library \\
\hline 8 & P. J. Hughes & 80 & Document Reference Section \\
\hline 9 & W. P. Levins & 81 & Laboratory Records-RC \\
\hline 10 & J. M. MacDonald & $82-84$ & Laboratory Records \\
\hline 11 & H. A. McLain & 85 & ORNL Patent Office \\
\hline 12 & D. E. Reichle & 86 & Laboratory Protection Division \\
\hline 13 & T. R. Sharp & 87 & ORNL Public Relations Office \\
\hline 14 & R. B. Shelton & & \\
\hline
\end{tabular}

\section{EXTERNAL DISTRIBUTION}

88-91 R. Anderson, 1617 Cole Blvd., Solar Energy Research Institute, Golden, CO 80401

92-101 M. Bailey, U.S. Department of Energy, EE-421, 1000 Independence Ave. S.W., Washington D.C. 20585

102 D. R. Bohi, Resources for the Future, 1616 P Street, N.W., Washington, DC 20036

103 K. Bond, DOE Kansas City Regional Support Office, 911 Walnut Suite 1411, Kansas City, MO 65106

104 M. Burger, DOE Chicago Regional Support Office, 9800 S. Cass Ave., Argonne, IL 60439

105 D. E. Claridge, Dept. of Mechanical Engineering, Texas A\&M University, College Station, TX 77843-3123

106-115 R. C. Diamond, Lawrence Berkeley Laboratory, MS-90-3074, 1 Cyclotron Rd, Berkeley, CA 94720

116 T. E. Drabek, Department of Sociology, University of Denver, Denver, CO 80208-0209

117 J. S. Haberl, Dept. of Architecture, Texas A\&M University, College Station, TX 778433581

118 D. Hawkins, U.S. Department of Energy, EE-40, 1000 Independence Ave. S.W., Washington D.C. 20585

119 H. M. Ingram, Udall Center for Studies in Public Policy, The University of Arizona, 803/811 East First St., Tucson, AZ 85719

120-129 C. Mather, Duke Power Co., 526 S. Church St., P.O. Box 1006, MS-EC12F, Charlotte, NC 28201-1006

130 W. R. Mixon, TECH Support Services, 1018 W. Outer Dr., Oak Ridge, TN 37830

131-132 M. P. Modera, Lawrence Berkeley Laboratory, MS-90-3074, 1 Cyclotron Rd, Berkeley, CA 94720

133 Steve Morgan, EUA Citizens Conservation Services, Inc., Boott Mills South, c/o EUA Cogenex Corp., 100 Foot of John St., Lowell, MA 01852-1197

134-143 M. Myers, U.S. Department of Energy, EE-421, 1000 Independence Ave. S.W., Washington D.C. 20585

144 R. Nadar, P.O. Box 19367, Washington D.C. 20036

145 T. A. Reddy, Dept. of Mechanical Engineering, Texas A\&M University, College Station, TX 77843-3123

146-150 W. F. Sandusky, Pacific Northwest Laboratory, MS K5-08, POB 999, Richland, WA 99352

151 G. F. Sowers, P.E., Senior Vice President, Law Companies Group, Inc., 114 Townpark Drive, Suite 250, Kennesaw, GA 30144-5599

152 C. M. Walton, Department of Civil Engineering, College of Engineering, The University of Texas, Cockrell Hall, Austin, TX 78712

153 Office of Assistant Manager for Energy Research and Development, DOE Oak Ridge Field Office, P.O. Box 2008, Oak Ridge, TN 37831-6269

154-155 OSTI, U.S. Department of Energy, P.O. Box 62, Oak Ridge, TN 37831 


